\title{
Molecular approaches for a better understanding of the epidemiology and population genetics of Leishmania
}

\author{
G. SCHÖNIAN ${ }^{1}$, K. KUHLS ${ }^{1}$ and I. L. MAURICIO ${ }^{2} \uparrow$ \\ ${ }^{1}$ Institute of Microbiology and Hygiene, Charité University Medicine Berlin, Dorotheenstrasse 96, D-10117 Berlin, \\ Germany \\ ${ }^{2}$ London School of Hygiene and Tropical Medicine, Keppel Street, WC1E 7HT London, UK
}

(Received 31 August 2010; revised 19 October 2010; accepted 19 October 2010; first published online 16 November 2010)

\begin{abstract}
SUMMARY
Molecular approaches are being used increasingly for epidemiological studies of visceral and cutaneous leishmaniases. Several molecular markers resolving genetic differences between Leishmania parasites at species and strain levels have been developed to address key epidemiological and population genetic questions. The current gold standard, multilocus enzyme typing (MLEE), needs cultured parasites and lacks discriminatory power. PCR assays identifying species directly with clinical samples have proven useful in numerous field studies. Multilocus sequence typing (MLST) is potentially the most powerful phylogenetic approach and will, most probably, replace MLEE in the future. Multilocus microsatellite typing (MLMT) is able to discriminate below the zymodeme level and seems to be the best candidate for becoming the gold standard for distinction of strains. Population genetic studies by MLMT revealed geographical and hierarchic population structure in L. tropica, L. major and the L. donovani complex. The existence of hybrids and gene flow between Leishmania populations suggests that sexual recombination is more frequent than previously thought. However, typing and analytical tools need to be further improved. Accessible databases should be created and sustained for integrating data obtained by different researchers. This would allow for global analyses and help to avoid biases in analyses due to small sample sizes.
\end{abstract}

Key words: Leishmania, molecular markers, phylogeny, population genetics, multilocus sequence typing, multilocus microsatellite typing.

\section{INTRODUCTION}

Representatives of the genus Leishmania cause a variety of clinical syndromes, ranging from selfhealing cutaneous forms (CL) through to mucocutaneous (MCL) and lethal visceral diseases (VL). The leishmaniases are transmitted via the bite of infected female sand flies of different Phlebotomus and Lutzomyia species and are widespread over the tropical and subtropical regions around the world. At least 21 species of Leishmania have been recorded as being infective to humans (WHO, 1990). There is no absolute correlation between a particular clinical form and causative species (Lainson and Shaw, 1998). Generally, parasites of the L. donovani complex are associated with VL in the Old and New Worlds but have also been found to cause CL. On the other hand, cases of VL have occasionally

* Corresponding author: Institute of Microbiology and Hygiene, Charité University Medicine Berlin, Campus Mitte, Dorotheenstrasse 96, D-10117 Berlin, Germany. Tel: + 4930 450524028. Fax: +49-30-450524902. E-mail: gabriele.schoenian@charite.de

$\uparrow$ Current address: Unidade de Parasitologia e Microbiologia Médicas, Instituto de Higiene e Medicina Tropical, Universidade Nova de Lisboa, R. da Junqueira 100, 1349-008 Lisboa, Portugal. been attributed to species usually recognized as causative agents of CL, such as L. tropica (see Sacks et al. 1995).

The current classification of Leishmania is still based on isoenzyme typing by using multilocus enzyme electrophoresis (MLEE), as reviewed by Schönian et al. (2008). This approach has been the most widely used technique during the past 25 years for the identification of Leishmania to species and subspecific levels. The MLEE methods used in Europe and in South America are, however, based on different enzyme panels and cannot be compared directly (Rioux et al. 1990; Cupolillo et al. 1994). In addition, MLEE has several limitations. Molecular studies have shown that differences in electrophoretic mobilities can be simply due to heterozygosity at a single nucleotide position (Jamjoom et al. 2004) or are not a consequence of nucleotide diversity of the particular gene (Mauricio et al. 2006; Zemanova et al . 2007). On the other hand, indistinguishable zymodeme phenotypes have been shown to be produced by distinct genotypes (Mauricio et al. 2006; Alam et al. 2009a). Consequently, other molecular studies do not always agree with the classification of Leishmania parasites by MLEE. For instance, the existence of 3 visceralizing species in East Africa, namely 
L. donovani, L. infantum and L. archibaldi, was not supported by analysis with many different molecular markers (Lukes et al. 2007), a separate species status was not confirmed for L. killicki (Schönian et al. 2001; Schwenkenbecher et al. 2006), and the L. donovani zymodeme MON-37 was assigned to strains of different genetic background (Alam et al. 2009a). The discriminatory power of MLEE for classifications below species level is limited because most of the L. infantum parasites causing visceral leishmaniasis in the Mediterranean and South America belong to the same zymodeme MON-1. Other important drawbacks of MLEE are that it requires bulk cultures of parasites, it is labour intensive and time-consuming, and it can only be performed in specialized laboratories.

Leishmaniasis is characterized not only by considerable clinical pleomorphism but also by varying epidemiology due to the remarkable diversity of Leishmania species and their vectors and, where applicable, their reservoir hosts. Recently, changes in the epidemiology of the leishmaniases have been reported from different endemic areas in the Old and New World. This includes amongst others, the emergence of new endemic foci (Karunaweera et al. 2003; Rhajaoui et al. 2007; Sharma et al. 2009): the spread of parasites to new areas (Jacobson et al. 2003; Capelli et al. 2004; Nasereddin et al. 2005); the sympatric presence of multiple species of Leishmania with overlapping clinical pictures (Al-Jawabreh et al. 2004; Sharma et al. 2005); the identification of new parasite-vector associations (Svobodova et al. 2006a), indications of anthroponotic transmission of $L$. infantum (Svobodova et al. 2009) and of zoonotic transmission for L. tropica (Svobodova et al. 2006b); and the isolation of new as yet unclassified members of the genus Leishmania from CL cases (Noyes et al. 2002; Villinski et al. 2008). The (re-)emergence and spread of these diseases observed worldwide have been attributed to 3 main risk factors: (i) environmental changes of human origin, (ii) immunosuppression, and (iii) treatment failure and drug resistance (Dujardin, 2006). A sound and consensual taxonomical background based on the knowledge of the population structure and phylogenetic diversity is needed for a better understanding of these epidemiological changes (Banuls et al. 1999). For this, reliable, reproducible and user-friendly tools are required that allow differentiation of Leishmania parasites at species and strain levels. Table 1 summarizes key epidemiological questions concerning the leishmaniases that can be addressed by species- and strainspecific markers.

MOLECULAR EPIDEMIOLOGY AND MOLECULAR MARKERS

Molecular epidemiology is the application of molecular tools to answer epidemiological questions, particularly for pathogens. Molecular data are mainly analysed in 2 different ways, by population genetics or phylogenetics. Population genetic analyses provide a snapshot of the current structure of genetic variation within and between populations whereas phylogenetic analyses present information on the history of populations or organisms in the form of trees or networks. Most published studies are based on empirical analyses and, unfortunately, population genetic or phylogenetic approaches to data analysis have as yet been rarely used. This is perhaps due to the fact that the analytical methods and most available software are not very user-friendly and/or not well-suited for thorough analyses of the large datasets produced by molecular epidemiological studies (Constantine, 2003; Tibayrenc, 2005).

Since the advent of PCR numerous molecular tools have been published that distinguish species and strains of Leishmania parasites. The tools range from the amplification and subsequent restriction fragment length polymorphism (RFLP) or DNA sequence analysis of multicopy targets or multigene families, including coding and non-coding regions and PCR-fingerprinting techniques, to the recently developed multilocus sequence typing (MLST) and multilocus microsatellite typing (MLMT) - for review see Schönian et al. (2008). Each of these molecular markers has its specific discriminatory power, advantages and drawbacks. The kind of marker that is most suitable depends on the research question to be asked (Table 1). This is especially important for the choice of the appropriate level of resolution. If the marker detects too much variation it may not faithfully represent more distant relationships and will fail to identify useful traits. If it is only moderately variable it will not explore the differences between closely related samples. Population genetic and phylogenetic approaches depend on neutral markers that are not affected by natural selection, although, in some situations non-neutral markers may identify a useful trait, e.g. virulence or drug resistance. Thus, markers should always be tested for neutrality. Co-dominant markers allowing for the detection of all 3 possible allele combinations in a diploid are preferred for population genetic studies. The markers should remain stable during in vitro or in vivo passage of the pathogens. The typing results should be reproducible, comparable between different laboratories and storable in databases. It should be possible to test intrinsic assumptions by comparing results from different methods of analyses and/or by examining the robustness of results using resampling techniques. The use of molecular markers directly in host tissues may be preferred because culture of Leishmania parasites often fails and may select for particular genotypes. Furthermore, direct methods facilitate sampling, although culture allows isolation of biological clones. Last but not least, since molecular epidemiological studies normally involve 
Table 1. Epidemiological questions to be addressed by tools differentiating Leishmania species and strains

\begin{tabular}{|c|c|c|c|c|c|c|}
\hline & MLEE $^{\mathrm{a}}$ & $\begin{array}{l}\text { Species } \\
\text { spec. PCR }\end{array}$ & $\begin{array}{l}\text { Genus-spec. PCR } \\
\text { (species id by RFLP, } \\
\text { hybridization, } \\
\text { sequencing, HRM) }\end{array}$ & $\begin{array}{l}\text { PCR RFLP } \\
\text { minicircle kDNA }\end{array}$ & MLST $^{\mathrm{c}}$ & MLMT $^{\mathrm{d}}$ \\
\hline \multicolumn{7}{|l|}{ Species typing } \\
\hline Identification of sympatric and imported species & $\mathbf{x}$ & $(\mathbf{x})$ & $\mathbf{x}$ & & $\mathbf{x}$ & \\
\hline Identification of species associated with treatment failure & $\mathbf{x}$ & $(\mathbf{x})$ & $\mathbf{x}$ & & $\mathbf{x}$ & \\
\hline Identification of new non-human reservoir hosts & $\mathbf{x}$ & $\mathbf{x}$ & $\mathbf{x}$ & & $\mathbf{x}$ & \\
\hline Incrimination of new phlebotomine vectors & $\mathbf{x}$ & $\mathbf{x}$ & $\mathbf{x}$ & & $\mathbf{x}$ & \\
\hline Detection of new parasite-insect-host-combinations & $\mathbf{x}$ & $\mathbf{x}$ & $\mathbf{x}$ & & $\mathbf{x}$ & \\
\hline Detection of hybrids & $\mathbf{x}$ & & & & $\mathbf{x}$ & \\
\hline \multicolumn{7}{|l|}{ Strain typing } \\
\hline Comparison of strains isolated from different hosts & $\mathbf{x}$ & & & $\mathbf{x}$ & & $\mathbf{x}$ \\
\hline Differentiation of zoonotic versus anthroponotic transmission cycles & $\mathbf{x}$ & & & $\mathbf{x}$ & & $\mathbf{x}$ \\
\hline Identification of new genotypes in mammal and insect hosts & $\mathbf{x}$ & & & $\mathbf{x}$ & & $\mathbf{x}$ \\
\hline Identification of the origins of new genotypes & $\mathbf{x}$ & & & & & $\mathbf{x}$ \\
\hline Search for genotypes related to drug resistance & & & & $\mathbf{x}$ & & $\mathbf{x}$ \\
\hline Differentiation between persistence or re-inoculation in relapses & & & & $\mathbf{x}$ & & $\mathbf{x}$ \\
\hline Detection of epidemics & $\mathbf{x}$ & & & $\mathbf{x}$ & & $\mathbf{x}$ \\
\hline Identification of sources of Leishmania & $\mathbf{x}$ & & & & & $\mathbf{x}$ \\
\hline Testing for population structure in Leishmania species & & & & & & $\mathbf{x}$ \\
\hline Testing for gene flow between populations and for hybrids & $\mathbf{x}$ & & & & $\mathbf{x}$ & $\mathbf{x}$ \\
\hline
\end{tabular}

Abbreviations: ${ }^{\mathrm{a}}$ MLEE, multilocus enzyme electrophoresis; ${ }^{\mathrm{b}}$ RFLP, restriction fragment length polymorphism; ${ }^{\mathrm{c}}$ MLST, multilocus sequence typing; ${ }^{\mathrm{d}}$ MLMT, multilocus microsatellite typing. (X) limited application. 
large sample sets, methods that are cost-effective and allow for high-throughput analyses are desirable.

How many markers are needed for molecular epidemiological and population genetic studies depends largely on the mode of reproduction. In clonal organisms, there is a correlation between the number of markers needed and the sample size to be investigated. Increasing the number of samples and loci will improve the estimates of genetic distance. However, if enough appropriate loci are available, reliable estimates of genetic distances can be obtained from few individuals (Kalinowski, 2005). In contrast, in recombining organisms larger sets of independent markers are needed to detect intraspecific variation since each locus might have a separate evolution. Frequent genetic recombination would result in unstable multilocus genotypes, in which case only individual genes can be analysed individually for epidemiological tracking (Tibayrenc, 2005) or tests applied should incorporate analysis of recombination. There may be, however, a limit to the number of useful markers. In clonal populations the number of different genotypes seems to increase linearly with an increase in the number of markers, whereas a plateau will be reached for recombining organisms, after which no more genotypes are uncovered even if more loci are added (Halkett et al.2005). Genetic exchange has recently been demonstrated in insect stages of Leishmania, but it seems to be sporadic in natural populations (Akopyants et al. 2009), although rates may vary between populations.

MOLECULAR MARKERS RESOLVINGLEISHMANIA PARASITES AT SPECIES LEVEL

The ability to distinguish between Leishmania species is crucial for the correct diagnosis and prognosis of the disease as well as for making decisions regarding treatment and control measures. This is especially useful for studies in areas with various co-existing Leishmania species such as the southern Mediterranean Basin where CL cases may be due to $L$. major, L. tropica or $L$. infantum or in South America where CL may be caused by L. mexicana and L. amazonensis as well as by the numerous often overlapping species of the subgenus L.(Viannia). In addition, due to increasing international travel and population migration Leishmania parasites are imported into other regions of the world, including areas non-endemic for the disease (Harms et al. 2003; Schönian et al. 2003; Johnston et al. 2009). Furthermore, the fact that lower trypanosomatids related to the monoxenous parasites of insects of the genera Leptomonas or Herpetomonas, have been identified as causative agents of VL in southern Europe (Jimenez et al. 1996), South America (Pacheco et al. 1998) and in the Indian subcontinent (Bhattarai et al. 2009) points to the need for species identification even in areas where, so far, only one species had been thought to cause the disease.

The advantage of molecular approaches based on PCR or other amplification techniques is that they combine high sensitivity for direct detection of the infecting parasites in various human, animal and sand fly tissues, with species specificity. Numerous PCR approaches have been published based on different coding and non-coding regions in the Leishmania genome, not all of them are, however, useful for identification at the species level. PCR assays amplifying the conserved region of kinetoplast minicircle DNA ( 10000 copies per cell) or SSU rDNA (40-200 copies per cell) have been shown to be most sensitive, but can identify leishmanial parasites only to the generic and/or subgeneric level (Van Eys et al. 1992; Yurchenko et al. 2000; Lachaud et al. 2002; Schönian et al. 2003; Disch et al. 2005; Bensoussan et al. 2006). On the other hand, amplification of species-specific DNA sequences (Salotra et al. 2001; Jirku et al. 2006; Laurent et al. 2009) has serious limitations if not combined with a genus-specific assay to rule out false negatives and co-infections with other Leishmania species or interspecific hybrid infections. In areas where many species are sympatric several different approaches might be necessary, which would increase the cost of diagnostics. Approaches based on initial amplification of genus-specific sequences followed by subsequent differentiation of Leishmania species by RFLP, hybridization with specific probes or sequencing of the amplified sequences have proven most useful. Different targets have been used for this, such as the ribosomal internal transcribed spacer (ITS) (Cupolillo et al. 1995; Schönian et al. 2003; Nasereddin et al. 2008); the mini-exon gene (Harris et al. 1998); repetitive nuclear DNA sequences (Piarroux et al. 1993); the glucose-6-phosphate dehydrogenase gene (Castilho et al. 2003); gp63 genes (Victoir et al. 1998); hsp70 genes (Garcia et al. 2004; Fraga et al. 2010); cytochrome b gene (Kato et al. 2005); and 7SL RNA gene sequences (Zelazny et al. 2005). Most laboratories use, however, an in-house PCR. Few research groups have tried to standardize and validate their PCR assay by testing for sensitivity and specificity not only with DNA extracted from cultured promastigotes but also with DNA extracted from different types of clinical material and from tissue samples spiked with known numbers of parasites, or by controlling for inhibition and the quality of DNA extraction, or by comparing their assays to other PCR assays (Schönian et al. 2003; Garcia et al. 2004; Bensoussan et al. 2006; Nasereddin et al. 2008).

To our knowledge, the PCR-RFLP of the internal transcribed spacer 1 (ITS1) is the most widely used assay for direct detection and identification of Leishmania species in the Old World. It has been applied to the distinction of sympatric species, 
especially in the Mediterranean region, as well as for the identification of imported cases (Harms et al. 2003; Al-Jawabreh et al. 2004; Rhajaoui et al. 2007). By digesting the ITS1 PCR product with only 1 restriction enzyme, HaeIII, all medically relevant Leishmania species can be distinguished. Representatives of the L. donovani complex (L. donovani and L. infantum) or L. braziliensis complex (L. braziliensis, L. guyanensis, L. panamensis, L. peruviana etc.) have almost identical RFLP patterns with a great variety of restriction enzymes and cannot be resolved further by this approach (Schönian et al. 2003). This problem can, however be solved by sequencing the 350 bp ITS1 PCR product (Schönian and Kuhls, unpublished observations) which, in the case of the L. donovani complex, not only allows for clear separation of $L$. infantum from $L$. donovani, but also assigns strains of these species to different phylogenetic groups supported by differences in biology and clinical behaviour (Kuhls et al. 2005). A recently developed simple reverse line blot hybridization (RLB) assay based on ITS1 sequences seems to be very promising for leishmaniasis diagnostics because it distinguishes all Old World Leishmania species, even $L$. donovani from $L$. infantum, with a 10 - to 100-fold enhanced sensitivity, comparable to that of kDNA PCR (Nasereddin et al. 2008). The primers used in these PCR assays amplify the ITS1 not only from all species of the genus Leishmania but also from other trypanosomatids, such as the genera Crithidia, Trypanosoma and Leptomonas (Schönian, unpublished observations). An ITS1 sequence that cannot be aligned to any of the Leishmania sequences available from GenBank might, therefore, be indicative for the presence of other trypanosomatids in the sample.

Recently, high-resolution melt (HRM) analysis of a real-time PCR product from the ITS1 region was used to identify and quantify Old World Leishmania species (Talmi-Frank et al. 2010). It is a closed tube assay that does not employ additional fluorescent probes but simply utilizes a DNA melting assay and computerized analysis of the results to produce a graphic output. When tested on 300 samples from human cases, reservoir hosts and sand flies, this approach distinguished all Old World Leishmania species causing human disease, except $L$. donovani from L. infantum.

The PCR-RFLP approach targeting $h s p 70$ sequences has proven to be most useful for the differentiation between South American Leishmania (Viannia) species. The restriction endonuclease HaeIII produces diagnostic RFLP patterns for the L. guyanensis species complex as well as for L. lainsoni and L. shawi (Garcia et al. 2004; Da Silva et al. 2010). However, L. braziliensis and L. peruviana, both belonging to the L. braziliensis complex, as well as L. naiff share an identical HaeIII RFLP pattern and can only be distingished by using a second restriction enzyme (Da Silva et al. 2010). The same is true for
L. guyanensis and L. panamensis both belonging to the L. guyanensis complex (Fraga et al. 2010). This discrimination is not only of epidemiological importance but has consequences for the prognosis of the disease. So far, MCL has been principally associated with L. braziliensis (Lessa et al. 2007), although other L. (Viannia) species have also been repeatedly suspected of causing MCL (Thomaz-Soccol et al. 2000). The $h s p 70$ PCR-RFLP has been successfully applied to direct identification of the infecting species in skin scrapings from Bolivian CL patients (Garcia et al. 2007a) and in sand fly pools during field studies in the Amazonian lowlands of Bolivia (Garcia et al. 2007b).

PCR assays combining detection of Leishmania parasites with species identification directly with clinical samples have proven useful in numerous field studies and should replace the current gold standard, multilocus enzyme electrophoresis (MLEE). The costs for PCR diagnosis are higher than for microscopy but comparable to those of culturing Leishmania. Species identification by PCR followed by RFLP, hybridization or sequencing is clearly less laborious and less costly than that by MLEE. However, the results of PCR diagnosis should always be evaluated in conjunction with clinical diagnosis, as PCR has been shown to be sensitive enough to detect parasite DNA in apparently parasitologically negative people living in areas endemic for leishmaniasis. A positive PCR result is thus a marker for infection or recent exposure rather than for disease (Deborggraeve et al. 2008a). However, the potential problem of PCR detecting naked DNA can probably be virtually disregarded, because Leishmania DNA has been shown to degrade quite quickly after the death of the parasites (Prina et al. 2007).

Assays using alternative amplification technologies such as quantitative nucleic acid sequence-based amplification (QT-NASBA) based on amplification of 18S RNA and loop-mediated isothermal amplification (LAMP) of kinetoplast minicircle DNA do not allow discrimination of different Leishmania species (Van der Meide et al. 2005; Takagi et al. 2009). Commercialized assays that have been developed for direct detection of Leishmania are not able to identify the infecting species. These commercial tests still rely on PCR for the amplification of the target and detection is achieved by hybridization to a genusspecific probe covalently linked to a dipstick (Deborggraeve et al. 2008b). Thus, for Leishmania species identification we still depend on validated inhouse PCR assays. The use of these assays requires careful selection, comparison and evaluation of reagents, proper training of the operators, a laboratory with some standard equipment, monitoring of quality control, and tests may not be readily applicable under field conditions.

An alternative technique, which might be promising for use in Leishmania, has been developed by 
Hamilton et al. (2008) for species identification in Trypanosoma. This method called fluorescent fragment length barcoding (FFLB) is based on length variation in regions of the $18 \mathrm{~S}$ and $28 \mathrm{~S} \alpha$ ribosomal DNA. Fluorescently tagged primers annealing to conserved regions were used to amplify fragments in the $18 \mathrm{~S}$ and $28 \mathrm{~S} \alpha$ ribosomal DNA with inter-species size variations. Sizes were accurately determined using an automated sequencer. By using 4 sets of primers amplifying 2 regions in each of the rRNA genes all trypanosome species could be distinguished and putative new species were recognized. FFLB has proven more sensitive than other PCR techniques and allows a high throughput of samples with up to 96 samples tested within $24 \mathrm{~h}$.

MOLECULAR MARKERS TO IDENTIFY

LEISHMANIA PARASITES AT STRAIN LEVEL

Different DNA-based techniques have been used to differentiate Leishmania parasites at the strain level. These include DNA and PCR fingerprinting approaches, e.g. Randomly Amplified Polymorphic DNA (RAPD) techniques, which require cultured parasites because probes and primers used in this context are not specific for Leishmania. DNA fingerprinting with the human multilocus minisatellite probe 33.15 was applied to follow an outbreak of VL in central Israel (Nasereddin et al. 2005). PCR fingerprinting and RAPD techniques have been successfully applied to characterize L. tropica strains in a new Israeli focus (Jacobson et al. 2003) as well as to detect intraspecies variation in the $L$. donovani complex (Hide et al. 2001; Zemanova et al. 2004). These techniques are relatively simple, rapid and do not need prior sequence information, but suffer from poor reproducibility. Importantly, the results are not comparable between laboratories.

Numerous epidemiological studies in leishmaniasis, only few of which can be cited here, have used PCR-RFLP approaches based on sequence polymorphisms in coding and non-coding regions of multigene families, including cysteine protease B $(c p B)$ (Garcia et al. 2005; Quispe-Tintaya et al. 2005); major surface glycoprotein ( $g$ p63) (Mauricio et al. 2001; Garcia et al. 2005); intergenic spacers of the ribosomal operon (Cupolillo et al. 1995, 2003; Schönian et al. 2001; Rotureau et al. 2006); miniexon sequences (Mauricio et al. 2004; Quispe Tintaya et al. 2004), and kinetoplast minicircles (Noyes et al. 1998; Morales et al. 2001; Chicharro et al. 2002; Cortes et al. 2006; Laurent et al. 2007). These approaches are relatively simple and rapid, and can be used directly with clinical isolates. The PCR-RFLP of whole minicircle DNA is a highly polymorphic assay that can differentiate between closely related organisms, such as L. infantum MON-1, and has been used to distinguish between recrudescence and re-infection (Morales et al. 2002). The fragment patterns obtained are, however, difficult to analyse. They are sometimes very complex and difficult to compare between laboratories and between different observers even when the same systems have been used. The patterns are not fully reproducible and artefacts due to partial restriction cannot be excluded. Finally, changes in the RFLP profiles have been observed during in vivo and in vitro passages of Leishmania parasites ('T. Laurent, personal communication). These techniques depend therefore, on careful standardization and are recommended for comparative studies involving few strains rather than for large-scale epidemiological studies. It should also be mentioned that in vitro selection for drug-resistant L. amazonensis lead to changes in $\mathrm{kDNA}$ minicircle RFLP due to a switch of minicircle class dominance (Lee et al. 1993). The minicircle RFLP pattern of Nepalese isolates of $L$. donovani did not, however, show any correlation with treatment outcome in patients (Laurent et al. 2007).

All the strain-specific DNA markers mentioned so far have one disadvantage in common, they are not co-dominant. The only co-dominant markers that currently differentiate within the Leishmania species and can detect all 3 diploid allele combinations possible in a diploid are MLEE, multilocus sequence typing (MLST) and multilocus microsatellite typing (MLMT). A detailed discussion of the latter 2 approaches is given in the next sections.

\section{MULTILOCUS SEQUENCE TYPING (MLST)}

Multilocus sequence typing (MLST) refers to analysis based on the DNA sequence of multiple gene targets. The term was adopted for a specific system developed initially for bacteria (Maiden et al. 1998) and which is applied like multilocus enzyme electrophoresis (MLEE). In the strict bacterial MLST context, short DNA sequences of 300$500 \mathrm{bp}$ for 7-12 targets are generated by direct sequencing in both directions. MLST is able to detect co-dominant single nucleotide polymorphisms (SNP), as mentioned above, and although indels can complicate the analysis and require cloning or other allele-specific analysis, in our experience they are extremely rare in protein-coding genes. Each sequence is scored as a haplotype, bacteria being haploid, and the combination of the haplotypes for all gene targets is the sequence type (ST). Targets must be selectively neutral, given that a single gene subject to high positive or negative selection may disrupt phylogenies. Sequence data are highly reproducible and easily comparable between laboratories and thus have been amenable to sharing in databases via the internet. A public website (www. mlst.net) is dedicated to host the web interface for most of such existing databases, hosted at Imperial College, UK. Via this and similar websites, users can perform several tasks such as downloading alleles and 
STs, comparing profiles to reference datasets and concatenating sequences. Users are encouraged to submit new alleles or STs to the curated database. A new development includes maps through which the global distribution of isolates and STs can be visualized by country in combination with Google Maps or Google Earth. Online access is also provided to data analysis software such as BURST, NRDB (Non-redundant databases), Splits'Tree and linkage disequilibrium.

Recently MLST has been applied to diploid organisms, notably to fungal pathogens of the genus Candida, in which case it is the diploid sequence type that is coded, using the codes for ambiguous nucleotides (Bougnoux et al. 2002). Diploids pose particular problems for analysis in that they possess 2 alleles per locus and there is no physical linkage between loci located in different chromosomes. Diploid MLST data may be analysed with programmes such as Splits Tree that accommodate ambiguous nucleotides or by concatenating datasets with duplicated nucleotides so that heterozygous sites become 2 sites with a single base at each. This latter method makes assumptions about the origin of each single nucleotide polymorphism (SNP), as identical nucleotides may be identical by descent (homologous) or by state (homoplasy) and should thus be used with caution.

In Leishmania, tentative steps have been taken to develop an MLST system, although an internet accessible database has not yet been created. The $L$. donovani complex has been studied by 2 sets of 5 loci for genes coding for enzymes used in MLEE (Mauricio et al. 2006; Zemanova et al. 2007): one set with asat, gpi, nh1, nh2 and pgd and the other with $i c d$, me, mpi, g6pdh, and fh. Together those 10 targets should form a complete MLST system applicable to the L. donovani complex. Although results from MLST of Leishmania are largely in agreement with the results from MLEE, some key discrepancies were found and increased resolution was obtained. Thus silent SNPs were found that provide further resolution, such a single SNP in $g p i$ that distinguishes between strains of L. infantum (Mauricio et al. 2006). However, SNPs responsible for amino acid changes were also found in genes coding for enzymes giving indistinguishable electrophoretic profiles, notably in $n h 2$, which has the same protein band size for all L. donovani complex strains.

Four gene targets ( $g p i$, $m d h, m p i$ and $6 p g d$ ) have been described for Leishmania of the New World (Tsukayama et al. 2009), not for analysis by MLST data, but for diagnostic tools. Unfortunately, the analysis did not include sufficient diversity of strains for each species, and unpublished analyses (Mauricio, unpublished observations; Cupolillo, personal communication) have shown that some potentially species-diagnostic SNPs are actually present in other species. In addition, 6 gene targets that are not associated with MLEE have been used to characterize L. major/L. infantum hybrids (Ravel et al. 2006), although their diversity within each species has not yet been published.

The main advantage of MLST over MLMT is the possibility of generating genus-wide phylogenies and, given high quality sequencing, unequivocal comparability between laboratories. Similar and further targets are being analysed for the subgenus Leishmania (Viannia), aiming to produce a share panel of MLST targets, although possibly with different primers, that can be applied to the entire genus. MLST is likely to become the gold standard basis for taxonomy and thus identification of Leishmania. For example, a preliminary analysis (Mauricio, unpublished observations) of the gene gpi for a number of samples of different species has shown that comparisons of genetic diversity within and across species may help decide on validity of controversial species. In comparison with MLEE, MLST does not necessarily require sterile culture of parasites, does not require simultaneous typing of reference strains, can be done commercially without in-house specialized equipment and, as mentioned above, the data are portable.

New generation sequencing (NGS) enables fast sequencing of large numbers of genes. MLST may be extended to 100 or more targets, including neutral targets and those known to have roles in key biological features such as virulence, drug resistance, shock resistance, etc. NGS on long read platforms also has the advantage of cloning samples so that reads are haplotypes and true heterozygotes can be distinguished from mixed samples. Such studies are likely to enhance in-depth knowledge of the natural history, evolution and population genetics of Leishmania.

MULTILOCUS MICROSATELLITE TYPING (MLMT)

Microsatellite sequences, also called simple sequence repeats (SSRs) or short tandem repeats (STRs), are repeated motifs of 1-6 nucleotides found in all eukaryotic and prokaryotic genomes (Toth et al. 2000; Mrazek et al. 2007). They are present in coding, albeit rarely, and in non-coding regions constitute a large fraction of sequences. Analysis of length polymorphisms of microsatellite-containing sequences has, recently, become an important tool for population and genetic studies of many species including humans. Microsatellites mutate at rates 5-6 orders of magnitude higher than the bulk of DNA, which makes them particularly useful for studying variation between closely related organisms. Microsatellite sequence variation results from the gain and loss of single repeat units, which can easily be detected after amplification with primers annealing specifically to their flanking regions. The results of these analyses are theoretically reproducible and 
exchangeable between laboratories. Selection does not seem to act on polymorphisms in microsatellite length, and allelic variants are detectable because of the co-dominant nature of these markers.

The mutation rate at a given microsatellite locus is influenced by various factors: the repeated motif itself, allele size, chromosome position, GC content in flanking DNA, and the efficacy of the mismatch repair system (MMR), which is critical for the stability of microsatellites. Recombination may change the repeat number by unequal crossing-over or by gene conversion (Li et al. 2002; Ellegren, 2004). However, the most plausible explanation for variation in repeat numbers is slippage of polymerase during DNA replication (Schlotterer and Tautz, 1992). The transient dissociation of the replicating DNA strands followed by misaligned re-association leads to gain or loss of repeat units. Most of these primary mutations in vivo are corrected by the MMR system, and only the small fraction that was not repaired or not correctly repaired ends up as variable microsatellites. Although there is a general tendency for gain of new repeats, natural selection acts against very long repeats (Li et al. 2002; Ellegren, 2004). This means that the evolutionary history of a particular repeat sequence may be uncertain and that these markers are prone to homoplasy. To overcome this main obstacle in the use of microsatellite analysis it is recommended that all studies should use a panel of 10-20 unlinked microsatellite markers.

The genome of Leishmania was found to be relatively rich in microsatellites with about 600 $(\mathrm{CA})_{\mathrm{n}}$ loci per haploid genome (Rossi et al. 1994). During recent years the development of microsatellite-based approaches has been attempted for strain typing within the genus Leishmania to overcome the lack of discriminatory power of MLEE and of many other molecular typing methods. It very soon became obvious that microsatellite markers highly discriminatory within one species of Leishmania could not be amplified, were even absent or not informative in others (Jamjoom et al. 2002a; Schwenkenbecher et al. 2004). Regions flanking the repeats were not strongly conserved between closely related species of Leishmania and repeats polymorphic in one species were often interrupted by single nucleotide substitutions and insertions in other species. Thus, speciesspecific and/or species-complex-specific marker sets are needed in the genus Leishmania.

So far, microsatellite loci with high discriminatory power and suitable for characterizing closely related strains have been published for the $L$. donovani complex (Bulle et al. 2002; Jamjoom et al. 2002b; Ochsenreither et al. 2006), L. major (Jamjoom et al. 2002a; Al-Jawabreh et al. 2008), L. tropica (Schwenkenbecher et al. 2006) and for species of the subgenus L. (Viannia) (Russell et al. 1999; Rougeron et al. 2008; Oddone et al. 2009). Recently, a searchable database of microsatellite loci within the genome has been established at http:// www.genomics.liv.ac.uk/tryps/Microsatellites.V1. html, which allows the development of more microsatellite markers for the L. donovani complex, L. major and L. braziliensis (Fakhar et al. 2008).

The multilocus microsatellite typing (MLMT) approaches developed so far for Leishmania make use of sets of 14-20 unlinked microsatellite loci. For application in large-scale epidemiological and population genetic studies, size variations of fluorescencelabelled PCR products should be detectable by using the fragment analysis tool of automated sequencers which have the potential for multiplexing and highthroughput analyses. Markers requiring sequence analysis of repeat number variation are not appropriate (Bulle et al. 2002) and, for that reason, most marker sets use primers closely flanking the repeat. Repeat numbers estimated for the different loci are assembled into a multilocus microsatellite profile for every strain under study.

Distance-based methods and models based on Bayesian statistics have been applied in the analysis of these profiles. Microsatellite based genetic distances may be calculated using the software MSA (Dieringer and Schlötterer, 2003) and POPULATIONS (http://bioinformatics.org/ tryphon/ populations) by applying different distance measures appropriate for microsatellites. Based on the resulting distance matrix Neighbour-joining (NJ) trees are constructed with programmes such as POPULATIONS and MEGA (Kumar et al. 2004). The model-based method to uncover population structure implemented in STRUCTURE (Pritchard et al. 2000) has advantages over distance-based data evaluation because its algorithm uses patterns of allele frequencies to identify distinct subpopulations and it determines fractions of each genotype within each subpopulation. However, panmixia is one of the essential assumptions in the STRUCTURE algorithm. Nevertheless, even if used with organisms not in Hardy-Weinberg equilibrium, STRUCTURE results have so far always corroborated those obtained by genetic distance, have accurately inferred individual ancestries, have been appropriate for characterization of population structure and have provided information on population relationships and history (e.g. see Schwenkenbecher et al. 2006; Al-Jawabreh et al. 2008; Wirth et al. 2008).

Once the population structure is defined, F-statistics are of high value for population studies of diploid organisms including Leishmania. $F_{i s}$, a measure of the inbreeding of individuals resulting from the deviation from panmixia, and $F_{s t}$, a measure of the relatedness between individuals due to the structure of the population, provide information about the mode of reproduction and population differentiation (De Meeus et al. 2006). Clonal diploids are expected to accumulate heterozygosity over time at every locus and should therefore exhibit negative $F_{i s}$ values. Heterozygote deficiency (positive 
$F_{i s}$ values) seen in many MLMT studies of Leishmania can be due to the presence of different factors, such as population subdivision (Wahlund effect) or a high rate of gene conversion. The impact of population substructure can be studied with the Bayesian analysis of genetic population structure (BAPS) software (Corander et al. 2007). Using this method Rougeron et al. (2009) have demonstrated that the high $F_{i s}$ values found in their MLMT analysis of Bolivian and Peruvian L. braziliensis are only partly explained by population subdivision.

It is advantageous that MLMT can be used directly on biological material without culture of the parasite. DNA extracted from specimens spotted on filter paper or glass slides or from old Giemsastained microscope slides was successfully applied in MLMT approaches (Alam et al. 2009b,c). Moreover, accurate, quality controlled microsatellite profiles can be stored in databases and compared between different laboratories.

POPULATION STRUCTURE OF KEY LEISHMANIA SPECIES AS REVEALED BY MLST AND MLMT

MLMT brought about the first true population genetics studies in Leishmania. The first study was done on L. tropica (Schwenkenbecher et al. 2006). It showed the existence of genetically different populations with geographical associations, as well as genetically isolated sympatric populations in rather small territories, e.g. in Israel and the Palestinian Authority and in Morocco. The population structure of L. tropica was found to be complex, with new variants spreading to distant foci, a zoonotic focus and with a heterozygous clade (putative hybrid lineage) achieving a widespread distribution. Unpublished MLST results by one of the authors (Mauricio) have shown consistency within groups identified by MLMT of L. tropica (Schwenkenbecher et al. 2006) and L. major (Al-Jawabreh et al. 2008).

Most of the MLMT studies published so far (Table 2) have addressed epidemiological and population genetic questions related to the $L$. donovani complex. A set of 15 microsatellite markers has been applied to type strains of $L$. donovani and L. infantum isolated from the main regions endemic for $\mathrm{VL}$ (Kuhls et al. 2007). Six principal genetically distinct populations were identified: 2 populations of L. infantum from the Mediterranean area and South America comprising the MON-1 and non-MON-1 strains, respectively; 2 populations of $L$. donovani from Sudan and Ethiopia; 1 of L. donovani MON-2 from India; and 1 consisting of strains of $L$. donovani (MON-36, 37, 38) from Kenya and India. This was perhaps not very surprising but corroborated the fragmentary data published in numerous studies using other genetic markers (Mauricio et al. 2004; Kuhls et al. 2005; Quispe-Tintaya et al. 2005;
Mauricio et al. 2007). Although 2 populations of L. donovani were found in Sudan and Ethiopia, like other molecular methods MLMT did not support the presence of other species, L. infantum and L. archibaldi, reported from MLEE in East Africa. Based on a combination of multiple genetic data, including MLMT data, a revised taxonomy was proposed for the L. donovani complex (Lukes et al. 2007).

MLST produced similar results and confirmed the division of the L. donovani complex into a number of genetic groups (Mauricio et al. 2006), equivalent to those found for MLMT (Kuhls et al. 2007). An exception was the subdivision of the Sudanese group, although one of these groups included strains placed in a separate MLST group. Notably, the MLST analysis was able to identify introgression of the ASAT allele typical of $L$. infantum into some Sudanese $L$. donovani strains, able to detect a strain with $L$. infantum/L.donovani gene mosaics, in addition to a clear hybrid between $2 \mathrm{~L}$. donovani subgroups, heterozygous at all genes with different alleles.

Interestingly, the highest microsatellite diversity was observed for L. infantum from the Mediterranean basin and the lowest for $L$. donovani from India. To test whether the latter finding might be attributed to a sampling bias or to the fact that a strain of L. infantum had been used for the design of the microsatellite markers used (Ochsenreither et al. 2006), we conducted a more comprehensive study by including more strains from India, Nepal and Bangladesh and by designing new microsatellite markers with a library made from an Indian strain of $L$. donovani (Alam et al. 2009c). The outcome was, however, the same, even when 34 additional microsatellite sequences had been analysed. The homogeneity of $L$. donovani from the Indian subcontinent was remarkable, 125 of the 132 strains tested belonged to the same population regardless of geographical origin, clinical manifestation, and whether they presented in vitro or in vivo susceptibility to antimonial drugs. Identical multilocus microsatellite profiles were found for 108 strains. The most plausible explanation is that this population emerged only recently with a very short time for subsequent evolution. However, MLST-based networks suggest sustained and ancient reproductive isolation from other L. donovani lineages. A bottleneck event related to the insecticide spraying under the Malaria Control programme in the 1960s might have exterminated the original $L$. donovani population(s) leaving only a small pocket of survivors that started to spread after the campaign was finished.

Because substructures were detected in the main populations of the L. donovani complex according to place and time of strain isolation (Kuhls et al. 2007) we attempted to use the MLMT for discriminating further the strains within the L. infantum MON-1 
Table 2. Overview of epidemiological and population genetic studies in leishmaniasis using MLMT

\begin{tabular}{llll}
\hline \hline Species & Parasites studied & $\begin{array}{l}\text { Sample } \\
\text { size }\end{array}$ & Outcome of the study
\end{tabular}

\section{Subgenus \\ Leishmania}

L. donovani complex

\section{L. infantum}

European strains of zymodeme MON-1 and other zymodemes

\section{L. infantum}

Algerian strains of zymodemes MON-1, MON-24 and MON-80

\section{L. infantum}

Tunisian strains of zymodemes MON-1, MON-24 and MON-80

Israeli and Palestinian
strains from dog and
human cases

L. infantum $\begin{gathered}\text { Uzbeki and Tajiki } \\ \text { parasites from huma } \\ \text { VL cases }\end{gathered}$
$\begin{aligned} & \text { Strains from Israel, } \\ & \text { Spain and France, } \\ & \text { mainly MON-1 }\end{aligned}$

L. infantum

Study of a focus (Priorat) in Spain

L. donovani
91
- 6 major geographical, genetically isolated populations,

- 4 populations of $L$. donovani (Sudan1 \& 2, India1 \& Kenya/ India2), 2 of L. infantum (MON-1 \& non-MON-1)

- allelic diversity highest in the Mediterranean, intermediate in Africa and lowest in India

- MON-1 strains clearly distinguished from non-MON-1

- Assignment of MON-1 strains to 3 geographical predominantly clonal populations

- Occasional recombination events and gene flow between populations

- 2 populations of mainly MON-1 strains, one of MON-24

- Gene flow and putative hybrids between the populations

- Differentiation between relapses and re-infection

- Hierarchical population structure: 2 main further sub-divided clusters of MON-1 and MON-24/-80 strains

- Hybrids between populations MON-1 and MON-24/-80

- Correlation to clinical disease in the MON-24/-80 cluster

- 2 main populations genetically different from European populations, one of which is sub-divided in geographically distributed sub-populations

- re-emergence of VL in old foci and introduction of parasites into new foci likely

- Identification as genetically distinct group of MON-1

- MLMT was performed on DNA samples extracted from Giemsa stained bone marrow aspirates

- 22 genotypes detected (in 10 microsatellite markers belonging to 3 different targets)

- 13 closely related genotypes for MON-1 strains

- high polymorphism in the Catalonian focus, low in Israel

- 17 genotypes detected (in 10 microsatellite markers belonging to 3 different targets)

- comparison of canine, human and sandfly genotypes

- One single monophyletic L. donovani clade in Sudan

- Isoenzyme differentiation of L. donovani and L. infantum in East Africa is misleading

- L. archibaldi is an invalid taxon
(Kuhls et al. 2007)

(Kuhls et al. 2008)

(Seridi et al. 2008)

(Chargui et al. 2009)

(Amro et al. 2009)

(Alam et al. 2009b)

(Bulle et al. 2002)

(Montoya et al. 2007)

(Jamjoom et al. 2004) 
Table 2. (Cont.)

\begin{tabular}{|c|c|c|c|c|}
\hline Species & Parasites studied & $\begin{array}{l}\text { Sample } \\
\text { size }\end{array}$ & Outcome of the study & Reference \\
\hline L. donovani & Strains from Sri Lanka & 11 & $\begin{array}{l}\text { - The causative agent of CL } \\
\text { in Sri Lanka is most closely } \\
\text { related to parasites causing VL } \\
\text { in the India }\end{array}$ & $\begin{array}{l}\text { (Siriwardana et al. } \\
\text { 2007) }\end{array}$ \\
\hline L. donovani & $\begin{array}{l}\text { Strains from India, } \\
\text { Bangladesh, Sri Lanka and } \\
\text { Nepal }\end{array}$ & 132 & $\begin{array}{l}\text { - Circulation of genetically } \\
\text { homogenous strains in the } \\
\text { Indian subcontinent probably } \\
\text { related to the epidemic spread } \\
\text { of VL } \\
\text { - Predominance of a single } \\
\text { genotype due to bottleneck } \\
\text { event? } \\
\text { - Three other genotypes/ } \\
\text { populations are circulating } \\
\text { - Bone marrow spotted on glass } \\
\text { slides and filter paper suitable } \\
\text { for microsatellite typing }\end{array}$ & (Alam et al. 2009c) \\
\hline L. donovani & $\begin{array}{l}\text { MON-37 strains of different } \\
\text { geographical origin }\end{array}$ & 15 & $\begin{array}{l}\text { - Zymodeme MON-37 is } \\
\text { paraphyletic, representing } \\
\text { different genetic groups } \\
\text { corresponding to their } \\
\text { geographical origin (India, } \\
\text { Sri Lanka, Middle East, } \\
\text { Cyprus, East Africa) } \\
\text { - Strains from Cyprus were clearly } \\
\text { different from all others and } \\
\text { could be autochthonous }\end{array}$ & (Alam et al. 2009a) \\
\hline L. tropica & Strains from Asia and Africa & 117 & $\begin{array}{l}\text { - } 10 \text { Genetic groups largely } \\
\text { correlating to the geographical } \\
\text { origin of the strains } \\
\text { - Different genetic groups co-exist } \\
\text { in Middle East and Morocco } \\
\text { - Recent spread of new genotypes } \\
\text { in the Middle East } \\
\text { - African origin of the species } \\
\text { L. tropica } \text { suspected }\end{array}$ & $\begin{array}{l}\text { (Schwenkenbecher } \\
\text { et al. 2006) }\end{array}$ \\
\hline L. major & $\begin{array}{l}\text { Strains from Central Asia, } \\
\text { Africa and the Middle East }\end{array}$ & 106 & $\begin{array}{l}\text { - } 3 \text { main geographical populations } \\
\text { (Central Asia, Africa, Middle } \\
\text { East, all subdivided into } \\
2 \text { sub-populations } \\
\text { - Central Asian population was } \\
\text { least genetically diversified }\end{array}$ & $\begin{array}{l}\text { (Al-Jawabreh et al. } \\
\text { 2008) }\end{array}$ \\
\hline \multicolumn{5}{|l|}{$\begin{array}{l}\text { subgenus } \\
\text { Viannia }\end{array}$} \\
\hline $\begin{array}{l}\text { L. braziliensis, } \\
\text { L. peruviana }\end{array}$ & Strains from Peru & 59 & $\begin{array}{l}\text { - Emergence of multiple } \\
\text { L. braziliensis } / L \text {. peruviana } \\
\text { hybrids }\end{array}$ & (Nolder et al. 2007) \\
\hline L. braziliensis & $\begin{array}{l}\text { Strains from Peru and } \\
\text { Bolivia }\end{array}$ & 124 & $\begin{array}{l}\text { - Substantial genetic diversity } \\
\text { - High levels of inbreeding } \\
\text { inconsistent with strictly clonal } \\
\text { reproduction } \\
\text { - Large genetic heterogeneity } \\
\text { between populations within } \\
\text { countries }\end{array}$ & (Rougeron et al. 2009) \\
\hline $\begin{array}{l}\text { L. braziliensis/ } \\
\text { L. guyanensis/ } \\
\text { L. peruviana }\end{array}$ & Brazil, Paraguay, Peru & 53 & $\begin{array}{l}\text { - } 3 \text { main clades (L. guyanensis, } \\
\text { L. braziliensis from east Brazil } \\
\text { and Paraguay and } \\
\text { L. braziliensis/peruviana from } \\
\text { Peru and north Brazil) } \\
\text { - further sub-division of main } \\
\text { clades according to geographical } \\
\text { origins of strains }\end{array}$ & (Oddone et al. 2009) \\
\hline
\end{tabular}


population. A big disadvantage of all previously used genetic approaches, except for kDNA-RFLP, was that they could not differentiate further the strains of this predominating zymodeme of L. infantum (up to $70 \%$ are MON-1). When we applied MLMT to 107 L. infantum MON-1 strains mainly from Portugal, Spain and Greece they were always at first separated from non-MON-1 strains included for comparison, but secondly split into 3 different populations comprising strains from Greece, the Balearic Islands and the Iberian peninsula, respectively (Kuhls et al. 2008).

Different genetic groups of strains of L. infantum were also observed when strains from Israel and the Palestinian Authority, Tunisia and Algeria were subjected to MLMT. In the 2 North African countries, different zymodemes of $L$. infantum can cause both visceral and cutaneous disease. Microsatellite typing of strains belonging to zymodemes MON-1, MON24 and MON-80 identified 3 different populations in both countries (Seridi et al. 2008; Chargui et al. 2009). The MON-1 strains were assigned to 2 different populations one of which contained only local strains and the other local and European strains of MON-1. The non-MON-1 strains were always separated from the MON-1. Gene flow was detected between the 2 MON-1 populations and the local MON-1 and the non-MON-1 populations, respectively. The existence of hybrid strains between different populations representing different zymodemes has been suspected in Algeria and was verified in Tunisia by analysis of clones of one of these strains.

The Israeli and Palestinian strains of L. infantum, all belonging to zymodeme MON-1, were assigned to 2 different populations (Amro et al. 2009). One population comprised all but one strain isolated from human and canine cases in the Palestinian West Bank and central Israel. The second population, consisting of canine isolates from central and northern Israel, was further divided into 3 subpopulations according to the place of isolation. Canine leishmaniasis (CanL) and human VL are re-emerging in central and northern Israel and in Palestinian foci, respectively. The re-emergence of $\mathrm{CanL}$ is most likely due to increased dog and human contact with sylvatic cycles of parasitic infection, whereas the spread of the second population towards the centre of Israel seems to result from recent introduction of parasites from older foci of northern Israel. Interestingly, none of the Israeli and Palestinian strains were found to group with European MON-1 or non-MON-1 strains.

A preliminary analysis of the MLMT profiles obtained for 398 strains of L. infantum uncovered a hierarchical population structure (Kuhls and Schonian, unpublished observations), with 3 different populations. One population included all nonMON-1 strains, which were from North Africa, with some from southwest Europe, but none from eastern Mediterranean foci. MON-1 strains were divided into 2 populations. One population had isolates from southwest Europe and South America and the other was of eastern and southern Mediterranean origin (Fig. 1). Both MON-1 populations showed further geographical clustering.

CONTRIBUTION OF MLST AND MLMT TO THE RESOLUTION OF MLEE ZYMODEMES

MLMT, and also MLST to a lesser extent, are further able to differentiate below the zymodeme level. As discussed above, MLMT revealed a remarkable genetic heterogeneity of $L$. infantum strains belonging to the zymodeme which is predominant in the Mediterranean area and in South America, MON-1. On the other hand, MLMT always assigned strains of zymodemes MON-77, 108 and 98 to the MON-1 cluster (Kuhls et al. 2008). This was confirmed by MLST for the zymodeme MON-98, for which the MLEE phenotype could not be explained by respective changes in the amino acid sequence (Zemanova et al. 2007).

MLMT, as well as MLST, has also resolved dramatic cases of MLEE convergence. Recently, strains of $L$. donovani MON-37 were identified as the causative agent of $\mathrm{VL}$ and $\mathrm{CL}$ cases in Cyprus (Antoniou et al. 2008). This zymodeme had previously been identified in Sri Lanka (Karunaweera et al. 2003) and earlier in India, Middle East and Kenya (Moreno et al. 1986; Moreno, 1989; Schnur et al. 2001). It was suggested that human migration had been responsible for the introduction of this zymodeme in both countries, previously unknown to be foci of L. donovani. However, the MON-37 strains from each location were found to be paraphyletic (Alam et al. 2009a). The ultimate origin of the different clades of this zymodeme, particularly in Cyprus, remains to be clarified.

CONTRIBUTIONS OF MLST AND MLMT TO THE 'CLONALITY $V S$ RECOMBINATION' DEBATE

Leishmania parasites are still thought to reproduce predominantly clonally, although there is growing evidence of gene flow and recombination (Mauricio et al. 2006; Kuhls et al. 2008; Akopyants et al. 2009; Chargui et al. 2009).

The high $F_{i s}$ values found in the MLMT analysis of Bolivian and Peruvian L. braziliensis (Rougeron et al. 2009) point to frequent sexual crosses of individuals from the same strain (inbreeding). The substantial heterozygote deficiency and extreme inbreeding found in this study is not consistent with a strictly clonal reproduction (Rougeron et al. 2009). Moreover, a strong population structure was found at a micro-geographical scale as the populations within the different countries were genetically heterogenous. This is in accord with the results of earlier population studies of L. infantum (Kuhls et al. 
non-MON-1

MON-1

MON-1
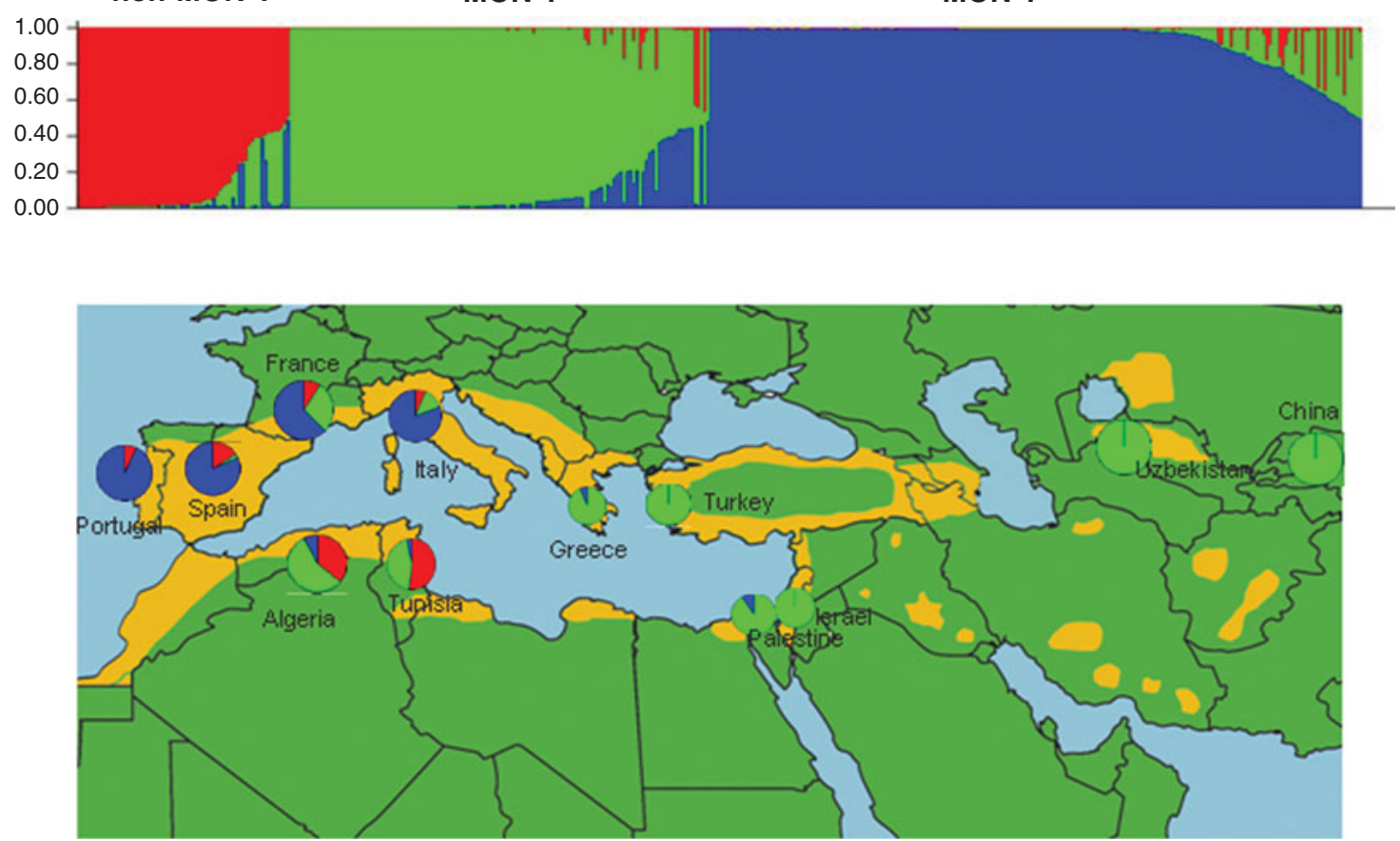

Fig. 1. MLMT analysis of 398 strains of Leishmania infantum revealed the existence of three main populations in the Mediterranean basin. According to data analysis based on Bayesian statistics (Structure software) the strains belonging to the predominating zymodeme MON-1 were assigned to two different populations, shown in green and blue, whereas all other strains (non-MON-1) grouped together in the red population. The charts show the percentages of strains belonging to respective populations. The MON-1 populations correlate with the geographical origin of the isolates.

2008; Seridi et al. 2008; Amro et al. 2009; Chargui et al.2009), L. tropica (Schwenkenbecher et al. 2006), and L. major (Al-Jawabreh et al. 2008). Recent research by MLMT on Sudanese L. donovani showed populations consistent with inbreeding, although it also detected the first population without departure from Hardy-Weinberg equilibrium (Baleela, personal communication). Moreover, the detection of strains with potential mosaic and heterozygous genotypes, and of hybrids within L. infantum - even between MON-1 and non-MON-1 populations, and of high inbreeding within and gene flow between the populations, pointed to at least occasional recombination events. Rougeron et al. (2009) came to the conclusion that Leishmania parasites may alternate between clonal and sexual modes of reproduction with the latter most probably occurring in the vector. Sexual fusion may frequently take place between genetically related parasites or even identical members of the same strain with occasional recombination events between individuals of different genotypes.

MLMT on parasites of the $L$. $(V$.$) braziliensis$ complex showed that recombination events are much more frequent in Leishmania than previously thought. L. braziliensis/L. peruviana hybrids were found to be quite common in a Peruvian focus where both species can occur sympatrically (Nolder et al. 2007). In some MCL patients the hybrids were the only organisms isolated. Whether the hybrids may give rise to epidemiologically important emergent genotypes needs to be further elucidated. Volf et al. (2007) demonstrated recently that L. infantum $/ L$. major hybrids could be transmitted by $\mathrm{Ph}$. papatasi which is normally only competent to transmit L. major. This suggests that the hybrids may circulate using this sand fly vector and spread into new foci throughout the broad range of $P h$. papatasi distribution.

MLST has so far been able to identify hybrids and genome mosaics (Mauricio et al. 2006; Zemanova et al. 2007) much more reliably than MLEE, and even MLMT, which is more prone to homoplasy. Such results have also suggested that recombination is likely to have been much more frequent historically and in extant populations, than previously recognized.

\section{CONCLUSIONS}

Global epidemiological, taxonomic and population genetic studies of Leishmania require good sampling strategies and appropriate molecular markers that allow discrimination at the desired genetic level. Markers that are stable during in vitro or in vivo passages and can be tested directly on clinical samples would be advantageous. The markers should accommodate test assumptions, comparisons with different analytic methods and assessment of robustness of results by using re-sampling techniques. The typing results should be reproducible, comparable between 
laboratories and storable in databases. Finally, highthroughput cost-effective methods are needed for large-scale studies. This is necessary since sampling should include isolates from many endemic foci, all possible hosts, and representing different zymodemes and clinical forms of the disease. Sample size is crucial as it has a direct effect on the ability to test hypotheses.

Answering key epidemiological questions requires new or improved tools that allow for differentiation of Leishmania parasites at species and strain levels. The current gold standard, MLEE, has some drawbacks, such as the need for cultured parasites and the lack of discriminatory power. At the species level, it should be replaced by PCR assays that enable direct detection and identification of different species of Leishmania in human and animal samples and in infected sand flies. Many of the PCR assays described in the literature have proven useful in numerous field studies. There is, however, an urgent need for standardization and validation of diagnostic PCR assays and for comparisons of the sensitivity and specificity of different approaches under routine conditions.

When different DNA-based methods of strain typing were compared, PCR-RFLP of kinetoplast minicircle DNA and MLMT were found to be most discriminatory at intra-species level, allowing further characterization of the parasite diversity and establishment of genetic links between remote populations of L. infantum and L. donovani (Botilde et al. 2006, Bhattarai et al. 2010). Because of its better reproducibility and possibility of data storage and exchange, MLMT currently seems to be the best candidate for becoming the gold standard for strain level differentiation. Since microsatellite markers are largely species-specific in Leishmania and different marker sets have to be used with different species, MLMT is not suited for inferring phylogeny.

Although less discriminatory, MLST is potentially the most powerful phylogenetic approach and will, most probably, advantageously replace MLEE in the future. Preliminary results show that the same targets can be used across the Leishmania genus which will enable comparisons of distances between the species but also of the degree of genetic diversity within species (Miles et al. 2009).

New high-throughput and cheaper sequencing technologies have opened the door for genome-wide multilocus genotyping in malaria research. Almost 47000 single nucleotide polymorphisms (SNPs) were identified across the Plasmodium genome (Volkman et al. 2007). This allowed development of microarray-based platforms for screening more than 3000 SNPs that were successfully applied for population genetic analyses and genome-wide association studies in P. falciparum (Neafsey et al. 2008; Mu et al. 2010). Research on Leishmania has already taken steps in similar directions, which are likely to finally enable researchers to answer some questions on population genetic questions, and ultimately tease out key aspects of drug resistance, virulence and other important issues relevant for control.

\section{ACKNOWLEDGEMENTS}

We are extremely grateful to all our collaborators, cited in the accompanying bibliography, for their friendship and support. We thank Michael Miles for his critical reading of the manuscript which helped to considerably improve it.

\section{FINANCIAL SUPPORT}

The work on which this review is based was funded in part by EC (contracts 01810 Leishmania genotyping and 015407 LeishEpiNetSA), the Deutsche Forschungsgemeinschaft (contracts Scho 448/6-1-3 and Scho 448/8-1), the Deutsche Akademische Austauschdienst and other financial contributors.

\section{REFERENCES}

Akopyants, N.S., Kimblin, N., Secundino, N., Patrick, R., Peters, N., Lawyer, P., Dobson, D. E., Beverley, S. M. and Sacks, D. L. (2009).

Demonstration of genetic exchange during cyclical development of Leishmania in the sand fly vector. Science 324, 265-268. doi:10.1126/science. 1169464

A1-Jawabreh, A., Schnur, L. F., Nasereddin, A., Schwenkenbecher, J. M., Abdeen, Z., Barghuthy, F., Khanfar, H., Presber, W. and Schönian, G. (2004). The recent emergence of Leishmania tropica in Jericho (A'riha) and its environs, a classical focus of L. major. Tropical Medicine and International Health 9, 812-816. doi:10.1111/j.13653156.2004.01268.x

Al-Jawabreh, A., Diezmann, S., Mueller, M., Wirth, T., Schnur, L. F., Strelkova, M. V., Kovalenko, D. A., Razakov, S. A., Schwenkenbecher, J., Kuhls, K. and Schoenian, G. (2008). Identification of geographically distributed subpopulations of Leishmania (Leishmania) major by microsatellite analysis. BMC Evolutionary Biology 8, 183. doi: 10.1186/1471-2148-8-183

Alam, M. Z., Haralambous, C., Kuhls, K., Gouzelou, E., Sgouras, D., Soteriadou, K., Schnur, L., Pratlong, F. and Schönian, G. (2009a). The paraphyletic composition of Leishmania donovani zymodeme MON-37 revealed by multilocus microsatellite typing. Microbes and Infection 11, 707-715. doi:10.1016/j.micinf.2009.04.009

Alam, M. Z., Kovalenko, D. A., Kuhls, K., Nasyrova, R. M., Ponomareva, V. I.,

Fatullaeva, A. A., Razakov, S. A., Schnur, L. F. and Schönian, G. (2009b). Identification of the agent causing visceral leishmaniasis in Uzbeki and Tajiki foci by analysing parasite DNA extracted from patients' Giemsa-stained tissue preparations. Parasitology 136, 981-986. doi:10.1017/S0031182009006465

Alam, M. Z., Kuhls, K., Schweynoch, C., Sundar, S., Rijal, S., Shamsuzzaman, A. K., Raju, B. V., Salotra, P., Dujardin, J. C. and Schönian, G. (2009c). Multilocus microsatellite typing (MLMT) reveals 
genetic homogeneity of Leishmania donovani strains in the Indian subcontinent. Infection, Genetics and Evolution 9, 24-31. doi:10.1016/j.meegid.2008.09.005

Amro, A., Schönian, G., A1-Sharabati, M. B., Azmi, K., Nasereddin, A., Abdeen, Z., Schnur, L. F., Baneth, G., Jaffe, C. L. and Kuhls, K. (2009). Population genetics of Leishmania infantum in Israel and the Palestinian Authority through microsatellite analysis. Microbes and Infection 11, 484-492. doi:10.1016/j. micinf.2009.02.001

Antoniou, M., Haralambous, C., Mazeris, A., Pratlong, F., Dedet, J. P. and Soteriadou, K. (2008). Leishmania donovani leishmaniasis in Cyprus. The Lancet Infectious Diseases 8, 6-7. doi:10.1016/S14733099(07)70297-9

Banuls, A. L., Hide, M. and Tibayrenc, M. (1999). Molecular epidemiology and evolutionary genetics of Leishmania parasites. International Fournal for Parasitology 29, 1137-1147. doi:10.1016/S0020-7519 (99)00083-1

Bensoussan, E., Nasereddin, A., Jonas, F., Schnur, L. F. and Jaffe, C. L. (2006). Comparison of PCR assays for diagnosis of cutaneous leishmaniasis. Fournal of Clinical Microbiology 44, 1435-1439. doi: 10.1128/JCM.44.4.1435-1439.2006

Bhattarai, N. R., Das, M. L., Rijal, S., Van der Auwera, G., Picado, A., Khanal, B., Roy, L., Speybroeck, N., Berkvens, D., Davies, C. R., Coosemans, M., Boelaert, M. and Dujardin, J. C. (2009). Natural infection of Phlebotomus argentipes with Leishmania and other Trypanosomatids in a visceral leishmaniasis endemic region of Nepal. Transactions of the Royal Society of Tropical Medicine and Hygiene 103, 1087-1092. doi:10.1016/j. trstmh.2009.03.008

Bhattarai, N. R., Dujardin, J. C., Rijal, S., De Doncker, S., Boelaert, M. and

Van der Auwera, G. (2010). Development and evaluation of different PCR-based typing methods for discrimination of Leishmania donovani isolates from Nepal. Parasitology 137, 947-957. doi: 10.1017/ S0031182009991752

Botilde, Y., Laurent, T., Quispe Tintaya, W., Chicharro, C., Canavate, C., Cruz, I., Kuhls, K., Schönian, G. and Dujardin, J. C. (2006). Comparison of molecular markers for strain typing of Leishmania infantum. Infection, Genetics and Evolution 6, 440-446. doi:10.1016/j.meegid.2006.02.003

Bougnoux, M. E., Morand, S. and D’Enfert, C. (2002). Usefulness of multilocus sequence typing for characterization of clinical isolates of Candida albicans. Fournal of Clinical Microbiology 40, 1290-1297. doi:10.1128/JCM.40.4.1290-1297.2002

Bulle, B., Millon, L., Bart, J. M., Gallego, M., Gambarelli, F., Portus, M., Schnur, L., Jaffe, C. L., Fernandez-Barredo, S., Alunda, J. M. and Piarroux, R. (2002). Practical approach for typing strains of Leishmania infantum by microsatellite analysis. Fournal of Clinical Microbiology 40, 3391-3397. doi:10.1128/JCM.40.9.3391-3397.2002

Capelli, G., Baldelli, R., Ferroglio, E., Genchi, C., Gradoni, L., Gramiccia, M., Maroli, M., Mortarino, M., Pietrobelli, M., Rossi, L. and Ruggiero, M. (2004). [Monitoring of canine leishmaniasis in northern Italy: an update from a scientific network]. Parassitologia 46, 193-197.

Castilho, T. M., Shaw, J. J. and Floeter-Winter, L. M. (2003). New PCR assay using glucose-6-phosphate dehydrogenase for identification of Leishmania species. Fournal of Clinical Microbiology 41, 540-546. doi:10.1128/JCM.41.2.540-546.2003

Chargui, N., Amro, A., Haouas, N., Schönian, G., Babba, H., Schmidt, S., Ravel, C., Lefebvre, M., Bastien, P., Chaker, E., Aoun, K., Zribi, M. and Kuhls, K. (2009). Population structure of Tunisian Leishmania infantum and evidence for the existence of hybrids and gene flow between genetically different populations. International Fournal for Parasitology 39, 801-811. doi:10.1016/j. ijpara.2008.11.016

Chicharro, C., Morales, M. A., Serra, T., Ares, M., Salas, A. and Alvar, J. (2002). Molecular epidemiology of Leishmania infantum on the island of Majorca: a comparison of phenotypic and genotypic tools. Transactions of the Royal Society of Tropical Medicine and Hygiene 96 (Suppl 1), S93-S99.

Constantine, C. C. (2003). Importance and pitfalls of molecular analysis to parasite epidemiology. Trends in Parasitology 19, 346-348. doi:10.1016/S1471-4922(03) 00167-3

Corander, J., Gyllenberg, M. and Koski, T. (2007). Random partition models and exchangeability for Bayesian identification of population structure. Bulletin of Mathematical Biology 69, 797-815. doi: 10.1007/ s11538-006-9161-1

Cortes, S., Mauricio, I., Almeida, A., Cristovao, J. M., Pratlong, F., Dedet, J. P. and Campino, L. (2006). Application of kDNA as a molecular marker to analyse Leishmania infantum diversity in Portugal. Parasitology International 55, 277-283. doi:10.1016/j. parint.2006.07.003

Cupolillo, E., Brahim, L. R., Toaldo, C. B., De Oliveira-Neto, M. P., De Brito, M. E., Falqueto, A., De Farias Naiff, M. and Grimaldi, G. jr. (2003). Genetic polymorphism and molecular epidemiology of Leishmania (Viannia) braziliensis from different hosts and geographic areas in Brazil. Fournal of Clinical Microbiology 41, 3126-3132. doi:10.1128/ JCM.41.7.3126-3132.2003

Cupolillo, E., Grimaldi, G. Jr. and Momen, H. (1994). A general classification of New World Leishmania using numerical zymotaxonomy. American Fournal of Tropical Medicine and Hygiene 50, 296-311.

Cupolillo, E., Grimaldi, G. Jr., Momen, H. and Beverley, S. M. (1995). Intergenic region typing (IRT): a rapid molecular approach to the characterization and evolution of Leishmania. Molecular and Biochemical Parasitology 73, 145-155.

Da Silva, L. A., De Sousa Cdos, S., Da Graca, G. C., Porrozzi, R. and Cupolillo, E. (2010). Sequence analysis and PCR-RFLP profiling of the hsp70 gene as a valuable tool for identifying Leishmania species associated with human leishmaniasis in Brazil. Infection, Genetics and Evolution 10, 77-83. doi:10.1016/j. meegid.2009.11.001

De Meeus, T., Lehmann, L. and Balloux, F. (2006). Molecular epidemiology of clonal diploids: a quick overview and a short DIY (do it yourself) notice. 
Infection, Genetics and Evolution 6, 163-170.

doi:10.1016/j.meegid.2005.02.004

Deborggraeve, S., Boelaert, M., Rijal, S., De Doncker, S., Dujardin, J. C., Herdewijn, P. and Buscher, P. (2008a). Diagnostic accuracy of a new Leishmania PCR for clinical visceral leishmaniasis in Nepal and its role in diagnosis of disease. Tropical Medicine and International Health 13, 1378-1383. doi:10.1111/j.1365-3156.2008.02154.x

Deborggraeve, S., Laurent, T., Espinosa, D., Van der Auwera, G., Mbuchi, M., Wasunna, M., El-Safi, S., Al-Basheer, A. A., Arevalo, J., MirandaVerastegui, C., Leclipteux, T., Mertens, P., Dujardin, J. C., Herdewijn, P. and Buscher, P. (2008b). A simplified and standardized polymerase chain reaction format for the diagnosis of leishmaniasis. The Fournal of Infectious Diseases 198, 1565-1572. doi:10.1086/592509

Dieringer, D. and Schlötterer, C. (2003). Microsatellite Analyser (MSA): a platform independent analysis tool for large microsatellite sets. Molecular Ecology Notes 3, 167-169. doi:10.1046/j.1471-8286.2003.00351.x

Disch, J., Pedras, M. J., Orsini, M., Pirmez, C., De Oliveira, M. C., Castro, M. and Rabello, A. (2005). Leishmania (Viannia) subgenus kDNA amplification for the diagnosis of mucosal leishmaniasis. Diagnostic Microbiology and Infectious Disease 51, 185-190. doi:10.1016/j.diagmicrobio.2004.10.005

Dujardin, J. C. (2006). Risk factors in the spread of leishmaniases: towards integrated monitoring? Trends in Parasitology 22, 4-6. doi:10.1016/j.pt.2005.11.004

Ellegren, H. (2004). Microsatellites: simple sequences with complex evolution. Nature Reviews Genetics 5, 435-445. doi:10.1038/nrg1348

Fakhar, M., Motazedian, M. H., Daly, D., Lowe, C. D., Kemp, S. J. and Noyes, H. A. (2008). An integrated pipeline for the development of novel panels of mapped microsatellite markers for Leishmania donovani complex, Leishmania braziliensis and Leishmania major.

Parasitology 135, 567-574. doi:10.1017/

S0031182008004186

Fraga, J., Montalvo, A. M., De Doncker, S., Dujardin, J. C. and Van der Auwera, G. (2010). Phylogeny of Leishmania species based on the heat-shock protein 70 gene. Infection, Genetics and Evolution 10, 238-245. doi:10.1016/j.meegid.2009.11.007

Garcia, L., Kindt, A., Bermudez, H., LlanosCuentas, A., De Doncker, S., Arevalo, J., Wilber Quispe Tintaya, K. and Dujardin, J. C. (2004). Culture-independent species typing of neotropical Leishmania for clinical validation of a PCR-based assay targeting heat shock protein 70 genes. Fournal of Clinical Microbiology 42, 2294-2297. doi:10.1128/

JCM.42.5.2294-2297.2004.

Garcia, A. L., Kindt, A., Quispe-Tintaya, K. W., Bermudez, H., Llanos, A., Arevalo, J., Banuls, A. L., De Doncker, S., Le Ray, D. and Dujardin, J. C. (2005). American tegumentary leishmaniasis: antigengene polymorphism, taxonomy and clinical pleomorphism. Infection, Genetics and Evolution 5, 109-116. doi:10.1016/j.meegid.2004.07.003

Garcia, A. L., Parrado, R., De Doncker, S., Bermudez, H. and Dujardin, J. C. (2007a). American tegumentary leishmaniasis: direct species identification of Leishmania in non-invasive clinical samples. Transactions of the Royal Society of Tropical Medicine and Hygiene 101, 368-371. doi:10.1016/j. trstmh.2006.06.009

Garcia, A. L., Tellez, T., Parrado, R., Rojas, E., Bermudez, H. and Dujardin, J. C. (2007b).

Epidemiological monitoring of American tegumentary leishmaniasis: molecular characterization of a peridomestic transmission cycle in the Amazonian lowlands of Bolivia. Transactions of the Royal Society of Tropical Medicine and Hygiene 101, 1208-1213. doi:10.1016/j.trstmh.2007.09.002

Halkett, F., Simon, J. C. and Balloux, F. (2005). Tackling the population genetics of clonal and partially clonal organisms. Trends in Ecology \& Evolution 20, 194-201. doi:10.1016/j.tree.2005.01.001

Hamilton, P. B., Adams, E. R., Malele, I. I. and Gibson, W. C. (2008). A novel, high-throughput technique for species identification reveals a new species of tsetse-transmitted trypanosome related to the Trypanosoma brucei subgenus, Trypanozoon. Infection, Genetics and Evolution 8, 26-33. doi:10.1016/j.meegid.2007.09.003

Harms, G., Schönian, G. and Feldmeier, H. (2003). Leishmaniasis in Germany. Emerging Infectious Diseases 9, 872-875.

Harris, E., Kropp, G., Belli, A., Rodriguez, B. and Agabian, N. (1998). Single-step multiplex PCR assay for characterization of New World Leishmania complexes. Fournal of Clinical Microbiology 36, 1989-1995.

Hide, M., Banuls, A. L. and Tibayrenc, M. (2001). Genetic heterogeneity and phylogenetic status of Leishmania (Leishmania) infantum zymodeme MON-1: epidemiological implications. Parasitology 123, 425-432.

Jacobson, R. L., Eisenberger, C. L., Svobodova, M., Baneth, G., Sztern, J., Carvalho, J., Nasereddin, A., El Fari, M., Shalom, U., Volf, P., Votypka, J., Dedet, J. P., Pratlong, F., Schönian, G., Schnur, L. F., Jaffe, C. L. and Warburg, A. (2003). Outbreak of cutaneous leishmaniasis in northern Israel. The Fournal of Infectious Diseases 188, 1065-1073. doi:10.1086/378204

Jamjoom, M. B., Ashford, R. W., Bates, P. A., Chance, M. L., Kemp, S. J., Watts, P. C. and Noyes, H. A. (2004). Leishmania donovani is the only cause of visceral leishmaniaisis in East Africa; previous descriptions of L. infantum and "L. archibaldi" from this region are a consequence of convergent evolution in the isoenzyme data. Parasitology 129, 399-409.

Jamjoom, M. B., Ashford, R. W., Bates, P. A., Kemp, S. J. and Noyes, H. A. (2002a). Polymorphic microsatellite repeats are not conserved between Leishmania donovani and Leishmania major. Molecular Ecology Notes 2, 104-106. doi:10.1046/j.14718286.2002.00161.x

Jamjoom, M. B., Ashford, R. W., Bates, P. A., Kemp, S. J. and Noyes, H. A. (2002b). Towards a standard battery of microsatellite markers for the analysis of the Leishmania donovani complex. Annals of Tropical Medicine and Parasitology 96, 265-270.

Jimenez, M. I., Lopez-Velez, R., Molina, R., Canavate, C. and Alvar, J. (1996). HIV co-infection with a currently non-pathogenic flagellate. Lancet 347, 264-265. 
Jirku, M., Zemanova, E., Al-Jawabreh, A., Schönian, G. and Lukes, J. (2006). Development of a direct species-specific PCR assay for differential diagnosis of Leishmania tropica. Diagnostic Microbiology and Infectious Disease 55, 75-79. doi:10.1016/j. diagmicrobio.2005.12.001

Johnston, V., Stockley, J. M., Dockrell, D., Warrell, D., Bailey, R., Pasvol, G., Klein, J., Ustianowski, A., Jones, M., Beeching, N. J., Brown, M., Chapman, A. L., Sanderson, F. and Whitty, C. J. (2009). Fever in returned travellers presenting in the United Kingdom: recommendations for investigation and initial management. Fournal of Infection 59, 1-18. doi:10.1016/j.jinf.2009.05.005

Kalinowski, S. T. (2005). Do polymorphic loci require large sample sizes to estimate genetic distances? Heredity 94, 33-36. doi:10.1038/sj.hdy.6800548

Karunaweera, N. D., Pratlong, F., Siriwardane, H. V., Ihalamulla, R. L. and Dedet, J. P. (2003). Sri Lankan cutaneous leishmaniasis is caused by Leishmania donovani zymodeme MON-37. Transactions of the Royal Society of Tropical Medicine and Hygiene $\mathbf{9 7}$, 380-381.

Kato, H., Uezato, H., Katakura, K., Calvopina, M., Marco, J. D., Barroso, P. A., Gomez, E. A., Mimori, T., Korenaga, M., Iwata, H., Nonaka, S. and Hashiguch, I. Y. (2005). Detection and identification of Leishmania species within naturally infected sand flies in the Andean areas of Ecuador by a polymerase chain reaction. American Fournal of Tropical Medicine and Hygiene 72, 87-93.

Kuhls, K., Chicharro, C., Canavate, C., Cortes, S., Campino, L., Haralambous, C., Soteriadou, K., Pratlong, F., Dedet, J. P., Mauricio, I., Miles, M., Schaar, M., Ochsenreither, S., Radtke, O. A. and Schönian, G. (2008). Differentiation and gene flow among European populations of Leishmania infantum MON-1. Plos Neglected Tropical Diseases 2, E261. doi:10.1371/journal.pntd.0000261

Kuhls, K., Keilonat, L., Ochsenreither, S., Schaar, M., Schweynoch, C., Presber, W. and Schönian, G. (2007). Multilocus microsatellite typing (MLMT) reveals genetically isolated populations between and within the main endemic regions of visceral leishmaniasis. Microbes and Infection 9, 334-343. doi:10.1016/j.micinf.2006.12.009

Kuhls, K., Mauricio, I. L., Pratlong, F., Presber, W. and Schönian, G. (2005). Analysis of ribosomal DNA internal transcribed spacer sequences of the Leishmania donovani complex. Microbes and Infection 7, 1224-1234. doi:10.1016/j.micinf.2005.04.009

Kumar, S., Tamura, K. and Nei, M. (2004). MEGA3: integrated software for molecular evolutionary genetics analysis and sequence alignment. Briefing in Bioinformatics 5, 150-163.

Lachaud, L., Marchergui-Hammami, S., Chabbert, E., Dereure, J., Dedet, J. P. and Bastien, P. (2002). Comparison of six PCR methods using peripheral blood for detection of canine visceral leishmaniasis. Fournal of Clinical Microbiology 40, 210-215. doi:10.1128/JCM.40.1.210-215.2002.

Lainson, R. and Shaw, J. J. (1998). New World leishmaniasis - the neotropical Leishmania species. In Topley $\mathcal{E}^{\circ}$ Wilson's Microbiology and Microbial Infections (ed. Cox, F. E. G., Kreier, J. P. and Wakelin, D.), pp. 241-266. Arnold, London, UK.

Laurent, T., Rijal, S., Yardley, V., Croft, S., De Doncker, S., Decuypere, S., Khanal, B., Singh, R., Schönian, G., Kuhls, K., Chappuis, F. and Dujardin, J. C. (2007). Epidemiological dynamics of antimonial resistance in Leishmania donovani: genotyping reveals a polyclonal population structure among naturally-resistant clinical isolates from Nepal. Infection, Genetics and Evolution 7, 206-212. doi:10.1016/j.meegid.2006.08.005

Laurent, T., Van der Auwera, G., Hide, M., Mertens, P., Quispe-Tintaya, W., Deborggraeve, S., De Doncker, S., Leclipteux, T., Banuls, A. L., Buscher, P. and Dujardin, J. C. (2009).

Identification of Old World Leishmania spp. by specific polymerase chain reaction amplification of cysteine proteinase B genes and rapid dipstick detection. Diagnostic Microbiology and Infectious Disease 63, 173-181. doi:10.1016/j. diagmicrobio.2008.10.015

Lee, S. T., Tarn, C. and Chang, K. P. (1993). Characterization of the switch of kinetoplast DNA minicircle dominance during development and reversion of drug resistance in Leishmania. Molecular and Biochemical Parasitology 58, 187-203.

Lessa, M. M., Lessa, H. A., Castro, T. W., Oliveira, A., Scherifer, A., Machado, P. and Carvalho, E. M. (2007). Mucosal leishmaniasis: epidemiological and clinical aspects. Brazilian Fournal of Otorhinolaryngology 73, 843-847.

Li, Y. C., Korol, A. B., Fahima, T., Beiles, A. and Nevo, E. (2002). Microsatellites: genomic distribution, putative functions and mutational mechanisms: a review. Molecular Ecology 11, 2453-2465. doi:10.1046/j.1365294X.2002.01643.x

Lukes, J., Mauricio, I. L., Schönian, G., Dujardin, J. C., Soteriadou, K., Dedet, J. P., Kuhls, K., Tintaya, K. W., Jirku, M., Chocholova, E., Haralambous, C., Pratlong, F., Obornik, M., Horak, A., Ayala, F. J. and Miles, M. A. (2007). Evolutionary and geographical history of the Leishmania donovani complex with a revision of current taxonomy. Proceedings of the National Academy of Sciences, USA 104, 9375-9380. doi:10.1073/pnas.0703678104

Maiden, M. C., Bygraves, J. A., Feil, E., Morelli, G., Russell, J. E., Urwin, R., Zhang, Q., Zhou, J., Zurth, K., Caugant, D. A., Feavers, I. M., Achtman, M. and Spratt, B. G. (1998). Multilocus sequence typing: a portable approach to the identification of clones within populations of pathogenic microorganisms. Proceedings of the National Academy of Sciences, USA 95, 3140-3145.

Mauricio, I. L., Gaunt, M. W., Stothard, J. R. and Miles, M. A. (2001). Genetic typing and phylogeny of the Leishmania donovani complex by restriction analysis of PCR amplified gp63 intergenic regions. Parasitology 122, 393-403.

Mauricio, I. L., Stothard, J. R. and Miles, M. A. (2004). Leishmania donovani complex: genotyping with the ribosomal internal transcribed spacer and the mini-exon. Parasitology 128, 263-267.

Mauricio, I. L., Gaunt, M. W., Stothard, J. R. and Miles, M. A. (2007). Glycoprotein 63 (gp63) genes show 
gene conversion and reveal the evolution of Old World Leishmania. International Fournal for Parasitology 37, 565-576. doi:10.1016/j.ijpara.2006.11.020

Mauricio, I. L., Yeo, M., Baghaei, M., Doto, D., Pratlong, F., Zemanova, E., Dedet, J. P., Lukes, J. and Miles, M. A. (2006). Towards multilocus sequence typing of the Leishmania donovani complex: resolving genotypes and haplotypes for five polymorphic metabolic enzymes (ASAT, GPI, NH1, NH2, PGD). International Fournal for Parasitology 36, 757-769. doi:10.1016/j.ijpara.2006.03.006

Miles, M. A., Llewellyn, M. S., Lewis, M. D., Yeo, M., Baleela, R., Fitzpatrick, S., Gaunt, M. W. and Mauricio, I. L. (2009). The molecular epidemiology and phylogeography of Trypanosoma cruzi and parallel research on Leishmania: looking back and to the future. Parasitology 136, 1509-1528. doi:10.1017/ S0031182009990977

Montoya, L., Gallego, M., Gavignet, B., Piarroux, R., Rioux, J. A., Portus, M. and Fisa, R. (2007).

Application of microsatellite genotyping to the study of a restricted Leishmania infantum focus: different genotype compositions in isolates from dogs and sand flies.

American Fournal of Tropical Medicine and Hygiene 76, 888-895.

Morales, M. A., Chicharro, C., Ares, M., Canavate, C., Barker, D. C. and Alvar, J. (2001). Molecular tracking of infections by Leishmania infantum. Transactions of the Royal Society of Tropical Medicine and Hygiene 95, 104-107.

Morales, M. A., Cruz, I., Rubio, J. M., Chicharro, C., Canavate, C., Laguna, F. and Alvar, J. (2002).

Relapses versus reinfections in patients coinfected with Leishmania infantum and human immunodeficiency virus type 1. The Fournal of Infectious Diseases 185, 1533-1537. doi:10.1086/340219

Moreno, G., Rioux, J. A., Lanotte, G., Pratlong, F. and Serres, E. (1986). Le complexe Leishmania donovani s.1. Analyse enzymatique et traitement numerique.

Individualisation du complexe L. infantum. Corollaires biogéographiques et phylogénetiques. A propos de 146 souches originaires de l'Ancien et du Nouveau Monde. In Leishmania. Taxonomie et Phylogénese. Applications éco-épidémiologiques (ed. Rioux, J. A.), pp. 105-117. IMEEE, Montpellier, France.

Moreno, G. (1989). Les complexes Leishmania donovani et Leishmania infantum. Implications taxonomiques, biogéographiques et épidémiologiques. A propos de l'analyse enzymatique de 548 souches de l'Ancien et du Nouveau Monde. Thesis University De Montpellier, France.

Mrazek, J., Guo, X. and Shah, A. (2007). Simple sequence repeats in prokaryotic genomes. Proceedings of the National Academy of Sciences, USA 104, 8472-8477. doi:10.1073/pnas.0702412104

Mu, J., Myers, R. A., Jiang, H., Liu, S., Ricklefs, S., Waisberg, M., Chotivanich, K., Wilairatana, P., Krudsood, S., White, N. J., Udomsangpetch, R., Cui, L., Ho, M., Ou, F., Li, H., Song, J., Li, G., Wang, X., Seila, S., Sokunthea, S., Socheat, D., Sturdevant, D. E., Porcella, S. F., Fairhurst, R. M., Wellems, T. E., Awadalla, P. and Su, X. Z. (2010). Plasmodium falciparum genome-wide scans for positive selection, recombination hot spots and resistance to antimalarial drugs. Nature Genetics 42, 268-271.

doi:10.1038/ng.528

Nasereddin, A., Baneth, G., Schönian, G., Kanaan, M. and Jaffe, C. L. (2005). Molecular fingerprinting of Leishmania infantum strains following an outbreak of visceral leishmaniasis in central Israel. Fournal of Clinical Microbiology 43, 6054-6059. doi:10.1128/

JCM.43.12.6054-6059.2005

Nasereddin, A., Bensoussan-Hermano, E., Schönian, G., Baneth, G. and Jaffe, C. L. (2008). Molecular diagnosis and species identification of Old World cutaneous leishmaniasis using a reverse line blot hybridization assay. Fournal of Clinical Microbiology 46, 2848-2855. doi:10.1128/JCM.00951-08

Neafsey, D. E., Schaffner, S. F., Volkman, S. K., Park, D., Montgomery, P., Milner, D. A., Jr. Lukens, A., Rosen, D., Daniels, R., Houde, N., Cortese, J. F., Tyndall, E., Gates, C., StangeThomann, N., Sarr, O., Ndiaye, D., Ndir, O., Mboup, S., Ferreira, M. U., Moraes Sdo, L., Dash, A. P., Chitnis, C. E., Wiegand, R. C., Hartl, D. L., Birren, B. W., Lander, E. S., Sabeti, P. C. and Wirth, D. F. (2008). Genome-wide SNP genotyping highlights the role of natural selection in Plasmodium falciparum population divergence. Genome Biology 9, R171. doi:10.1186/gb-2008-9-12-r171

Nolder, D., Roncal, N., Davies, C. R., LlanosCuentas, A. and Miles, M. A. (2007). Multiple hybrid genotypes of Leishmania (Viannia) in a focus of mucocutaneous leishmaniasis. American Fournal of Tropical Medicine and Hygiene 76, 573-578.

Noyes, H., Pratlong, F., Chance, M., Ellis, J., Lanotte, G. and Dedet, J. P. (2002). A previously unclassified trypanosomatid responsible for human cutaneous lesions in Martinique (French West Indies) is the most divergent member of the genus Leishmania ss. Parasitology 124, 17-24.

Noyes, H. A., Reyburn, H., Bailey, J. W. and Smith, D. (1998). A nested-PCR-based schizodeme method for identifying Leishmania kinetoplast minicircle classes directly from clinical samples and its application to the study of the epidemiology of Leishmania tropica in Pakistan. Fournal of Clinical Microbiology 36, 2877-2881.

Ochsenreither, S., Kuhls, K., Schaar, M., Presber, W. and Schönian, G. (2006). Multilocus microsatellite typing as a new tool for discrimination of Leishmania infantum MON-1 strains. Fournal of Clinical Microbiology 44, 495-503. doi:10.1128/ JCM.44.2.495-503.2006

Oddone, R., Schweynoch, C., Schönian, G., De Sousa Cdos, S., Cupolillo, E., Espinosa, D., Arevalo, J., Noyes, H., Mauricio, I. and Kuhls, K. (2009). Development of a multilocus microsatellite typing approach for discriminating strains of Leishmania (Viannia) species. Fournal of Clinical Microbiology 47, 2818-2825. doi:10.1128/JCM.00645-09

Pacheco, R. S., Marzochi, M. C., Pires, M. Q., Brito, C. M., Madeira Mde, F. and BarbosaSantos, E. G. (1998). Parasite genotypically related to a monoxenous trypanosomatid of dog's flea causing opportunistic infection in an HIV positive patient. Memórias do Instituto Oswaldo Cruz 93, 531-537.

Piarroux, R., Azaiez, R., Lossi, A. M., Reynier, P., Muscatelli, F., Gambarelli, F., Fontes, M., 
Dumon, H. and Quilici, M. (1993). Isolation and characterization of a repetitive DNA sequence from Leishmania infantum: development of a visceral leishmaniasis polymerase chain reaction. American Fournal of Tropical Medicine and Hygiene 49, 364-369.

Prina, E., Roux, E., Mattei, D. and Milon, G. (2007). Leishmania DNA is rapidly degraded following parasite death: an analysis by microscopy and real-time PCR. Microbes and Infection 9, 1307-1315. doi:10.1016/j. micinf.2007.06.005

Pritchard, J. K., Stephens, M. and Donnelly, P. (2000). Inference of population structure using multilocus genotype data. Genetics 155, 945-959.

Quispe Tintaya, K. W., Ying, X., Dedet, J. P., Rijal, S., De Bolle, X. and Dujardin, J. C. (2004). Antigen genes for molecular epidemiology of leishmaniasis: polymorphism of cysteine proteinase $\mathrm{B}$ and surface metalloprotease glycoprotein 63 in the Leishmania donovani complex. The Fournal of Infectious Diseases 189, 1035-1043. doi:10.1086/382049

Quispe Tintaya, K. W., Laurent, T., Decuypere, S., Hide, M., Banuls, A. L., De Doncker, S., Rijal, S., Canavate, C., Campino, L. and Dujardin, J. C. (2005). Fluorogenic assay for molecular typing of the Leishmania donovani complex: taxonomic and clinical applications. The Fournal of Infectious Diseases 192, 685-692. doi:10.1086/432077

Ravel, C., Cortes, S., Pratlong, F., Morio, F., Dedet, J. P. and Campino, L. (2006). First report of genetic hybrids between two very divergent Leishmania species: Leishmania infantum and Leishmania major. International Fournal for Parasitology 36, 1383-1388. doi:10.1016/j.ijpara.2006.06.019

Rhajaoui, M., Nasereddin, A., Fellah, H., Azmi, K., Amarir, F., Al-Jawabreh, A., Ereqat, S., Planer, J. and Abdeen, Z. (2007). New clinico-epidemiologic profile of cutaneous leishmaniasis, Morocco. Emerging Infectious Diseases 13, 1358-1360.

Rioux, J. A., Lanotte, G., Serres, E., Pratlong, F., Bastien, P. and Perieres, J. (1990). Taxonomy of Leishmania. use of isoenzymes. suggestions for a new classification. Annales de Parasitologie Humaine et Comparee 65, 111-125.

Rossi, V., Wincker, P., Ravel, C., Blaineau, C., Pages, M. and Bastien, P. (1994). Structural organisation of microsatellite families in the Leishmania genome and polymorphisms at two (CA)n loci. Molecular and Biochemical Parasitology 65, 271-282.

Rotureau, B., Ravel, C., Nacher, M., Couppie, P., Curtet, I., Dedet, J. P. and Carme, B. (2006). Molecular epidemiology of Leishmania (Viannia) guyanensis in French Guiana. Fournal of Clinical Microbiology 44, 468-473. doi:10.1128/JCM.44.2.468473.2006

Rougeron, V., Waleckx, E., Hide, M., De Meeûs, T., Arevalo, J., Llanos-Cuentas, A. and Banuls, A. L. (2008). A set of 12 microsatellite loci for genetic studies of Leishmania braziliensis. Molecular Ecology Resources 8, 351-353. doi:10.1111/j.1471-8286.2007.01953.x

Rougeron, V., De Meeus, T., Hide, M., Waleckx, E., Bermudez, H., Arevalo, J., Llanos-Cuentas, A., Dujardin, J. C., De Doncker, S., Le Ray, D., Ayala, F. J. and Banuls, A. L. (2009). Extreme inbreeding in Leishmania braziliensis. Proceedings of the National Academy of Sciences, USA 106, 10224-10229. doi:10.1073/pnas.0904420106

Russell, R., Iribar, M. P., Lambson, B., Brewster, S., Blackwell, J. M., Dye, C. and Ajioka, J. W. (1999). Intra and inter-specific microsatellite variation in the Leishmania subgenus Viannia. Molecular and Biochemical Parasitology 103, 71-77. doi:10.1016/ S0166-6851(99)00117-6

Sacks, D. L., Kenney, R. T., Kreutzer, R. D., Jaffe, C. L., Gupta, A. K., Sharma, M. C., Sinha, S. P., Neva, F. A. and Saran, R. (1995). Indian kala-azar caused by Leishmania tropica. Lancet 345, 959-961. doi:10.1016/S0140-6736(95)90703-3

Salotra, P., Sreenivas, G., Pogue, G. P., Lee, N., Nakhasi, H. L., Ramesh, V. and Negi, N. S. (2001). Development of a species-specific PCR assay for detection of Leishmania donovani in clinical samples from patients with kala-azar and post-kala-azar dermal leishmaniasis. Fournal of Clinical Microbiology 39, 849-854. doi:10.1128/ JCM.39.3.849-854.2001

Schlotterer, C. and Tautz, D. (1992). Slippage synthesis of simple sequence DNA. Nucleic Acids Research 20, 211-215.

Schnur, L. F., Eisenberger, C., Nasereddin, A., Dedet, J.-P., Pratlong, F., Jaffe, C. J. and Benami, R. (2001). Adult visceral leishmaniasis caused by Leishmania donovani senso stricto acquired locally in Israel. In 2nd World Congress on Leishmaniasis. pp. 20. Hersonissos, Crete, Greece.

Schönian, G., Mauricio, I., Gramiccia, M., Canavate, C., Boelaert, M. and Dujardin, J. C. (2008). Leishmaniases in the Mediterranean in the era of molecular epidemiology. Trends in Parasitology 24, 135-142. doi:10.1016/j.pt.2007.12.006

Schönian, G., Nasereddin, A., Dinse, N., Schweynoch, C., Schallig, H. D., Presber, W. and Jaffe, C. L. (2003). PCR diagnosis and characterization of Leishmania in local and imported clinical samples. Diagnostic Microbiology and Infectious Disease 47, 349-358. doi:10.1016/S0732-8893(03)00093-2

Schönian, G., Schnur, L., El Fari, M., Oskam, L., Kolesnikov, A. A., Sokolowska-Kohler, W. and Presber, W. (2001). Genetic heterogeneity in the species Leishmania tropica revealed by different PCR-based methods. Transactions of the Royal Society of Tropical Medicine and Hygiene 95, 217-224.

Schwenkenbecher, J. M., Frohlich, C., Gehre, F., Schnur, L. F. and Schönian, G. (2004). Evolution and conservation of microsatellite markers for Leishmania tropica. Infection, Genetics and Evolution 4, 99-105. doi:10.1016/j.meegid.2004.01.005

Schwenkenbecher, J. M., Wirth, T., Schnur, L. F., Jaffe, C. L., Schallig, H., Al-Jawabreh, A., Hamarsheh, O., Azmi, K., Pratlong, F. and Schönian, G. (2006). Microsatellite analysis reveals genetic structure of Leishmania tropica. International Fournal for Parasitology 36, 237-246. doi:10.1016/ j.ijpara.2005.09.010

Seridi, N., Amro, A., Kuhls, K., Belkaid, M., Zidane, C., Al-Jawabreh, A. and Schönian, G. (2008). Genetic polymorphism of Algerian Leishmania infantum strains revealed by multilocus microsatellite 
analysis. Microbes and Infection 10, 1309-1315. doi:10.1016/j.micinf.2008.07.031

Sharma, N. L., Mahajan, V. K., Kanga, A., Sood, A., Katoch, V. M., Mauricio, I., Singh, C. D., Parwan, U. C., Sharma, V. K. and Sharma, R. C. (2005). Localized cutaneous leishmaniasis due to Leishmania donovani and Leishmania tropica: preliminary findings of the study of 161 new cases from a new endemic focus in Himachal Pradesh, India. American Fournal of Tropical Medicine and Hygiene 72, 819-824.

Sharma, N. L., Mahajan, V. K., Ranjan, N., Verma, G. K., Negi, A. K. and Mehta, K. I. (2009). The sandflies of the Satluj River Valley, Himachal Pradesh (India): some possible vectors of the parasite causing human cutaneous and visceral leishmaniases in this endemic focus. Fournal of Vector Borne Diseases 46, $136-140$

Svobodova, M., Alten, B., Zidkova, L., Dvorak, V., Hlavackova, J., Myskova, J., Seblova, V., Kasap, O. E., Belen, A., Votypka, J. and Volf, P. (2009). Cutaneous leishmaniasis caused by Leishmania infantum transmitted by Phlebotomus tobbi. International Fournal for Parasitology 39, 251-256. doi:10.1016/j. ijpara.2008.06.016

Svobodova, M., Volf, P. and Votypka, J. (2006b). Experimental transmission of Leishmania tropica to hyraxes (Procavia capensis) by the bite of Phlebotomus arabicus. Microbes and Infection 8, 1691-1694. doi:10.1016/j.micinf.2006.01.024

Svobodova, M., Votypka, J., Peckova, J., Dvorak, V., Nasereddin, A., Baneth, G., Sztern, J., Kravchenko, V., Orr, A., Meir, D., Schnur, L. F., Volf, P. and Warburg, A. (2006a). Distinct transmission cycles of Leishmania tropica in 2 adjacent foci, northern Israel. Emerging Infectious Diseases 12, 1860-1868.

Takagi, H., Itoh, M., Islam, M. Z., Razzaque, A., Ekram, A. R., Hashighuchi, Y., Noiri, E. and Kimura, E. (2009). Sensitive, specific, and rapid detection of Leishmania donovani DNA by loop-mediated isothermal amplification. American Fournal of Tropical Medicine and Hygiene 81, 578-582. doi:10.4269/ajtmh.2009.09-0145

Talmi-Frank, D., Nasereddin, A., Schnur, L. F., Schonian, G., Toz, S. O., Jaffe, C. L. and Baneth, G. (2010). Detection and identification of Old World Leishmania by high resolution melt analysis. Plos Neglected Tropical Diseases 4, E581. doi:10.1371/ journal.pntd.0000581

Thomaz-Soccol, V., Velez, I. D., Pratlong, F., Agudelos, S., Lanotte, G. and Rioux, J. A. (2000). Enzymatic polymorphism and phylogenetic relationships in Leishmania Ross, 1903 (Sarcomastigophora: Kinetoplastida): a case study in Colombia. Systematic Parasitology 46, 59-68. doi:10.1023/A:1006379309576

Tibayrenc, M. (2005). Bridging the gap between molecular epidemiologists and evolutionists. Trends in Microbiology 13, 575-580. doi:10.1016/j. tim.2005.09.004

Toth, G., Gaspari, Z. and Jurka, J. (2000). Microsatellites in different eukaryotic genomes: survey and analysis. Genome Research 10, 967-981. doi:10.1101/gr.10.7.967
Tsukayama, P., Lucas, C. and Bacon, D. J. (2009). Typing of four genetic loci discriminates among closely related species of New World Leishmania. International Fournal for Parasitology 39, 355-362. doi:10.1016/j. ijpara.2008.08.004

Van der Meide, W. F., Schoone, G. J., Faber, W. R., Zeegelaar, J. E., De Vries, H. J., Ozbel, Y., Lai, A. F. R. F., Coelho, L. I., Kassi, M. and Schallig, H. D. (2005). Quantitative nucleic acid sequence-based assay as a new molecular tool for detection and quantification of Leishmania parasites in skin biopsy samples. Fournal of Clinical Microbiology 43, 5560-5566. doi:10.1128/ JCM.43.11.5560-5566.2005

Van Eys, G. J., Schoone, G. J., Kroon, N. C. and Ebeling, S. B. (1992). Sequence analysis of small subunit ribosomal RNA genes and its use for detection and identification of Leishmania parasites. Molecular and Biochemical Parasitology 51, 133-142.

Victoir, K., Banuls, A. L., Arevalo, J., LlanosCuentas, A., Hamers, R., Noel, S., De Doncker, S., Le Ray, D., Tibayrenc, M. and Dujardin, J. C. (1998). The gp63 gene locus, a target for genetic characterization of Leishmania belonging to subgenus Viannia . Parasitology 117, 1-13.

Villinski, J. T., Klena, J. D., Abbassy, M., Hoel, D. F., Puplampu, N., Mechta, S., Boakye, D. and Raczniak, G. (2008). Evidence for a new species of Leishmania associated with a focal disease outbreak in Ghana. Diagnostic Microbiology and Infectious Disease 60, 323-327. doi:10.1016/j.

diagmicrobio.2007.09.013

Volf, P., Benkova, I., Myskova, J., Sadlova, J., Campino, L. and Ravel, C. (2007). Increased transmission potential of Leishmania major/Leishmania infantum hybrids. International Fournal for Parasitology 37, 589-593. doi:10.1016/j.ijpara.2007.02.002

Volkman, S. K., Sabeti, P. C., DeCaprio, D., Neafsey, D. E., Schaffner, S. F., Milner, D. A., Jr. Daily, J. P., Sarr, O., Ndiaye, D., Ndir, O., Mboup, S., Duraisingh, M. T., Lukens, A., Derr, A., Stange-Thomann, N., Waggoner, S., Onofrio, R., Ziaugra, L., Mauceli, E., Gnerre, S., Jaffe, D. B., Zainoun, J., Wiegand, R. C., Birren, B. W., Hart1, D. L., Galagan, J. E., Lander, E. S. and Wirth, D. F. (2007). A genome-wide map of diversity in Plasmodium falciparum. Nature Genetics 39, 113-119. doi:10.1038/ng1930

World Health Organization (1990). Control of the leishmaniasis. Report of a WHO Expert Committee. WHO Expert Committee on the Control of the Leishmaniases, World Health Organization, Geneva, Switzerland.

Wirth, T., Hildebrand, F., Allix-Beguec, C., Wolbeling, F., Kubica, T., Kremer, K., Van Soolingen, D., Rusch-Gerdes, S., Locht, C., Brisse, S., Meyer, A., Supply, P. and Niemann, S. (2008). Origin, spread and demography of the Mycobacterium tuberculosis complex. PLoS Pathogens 4, E1000160. doi:10.1371/journal.ppat.1000160

Yurchenko, V., Kolesnikov, A. A. and Lukes, J. (2000). Phylogenetic analysis of Trypanosomatina (Protozoa: Kinetoplastida) based on minicircle conserved regions. Folia Parasitologica (Praha) 47, 1-5. 
Zelazny, A. M., Fedorko, D. P., Li, L., Neva, F. A. and Fischer, S. H. (2005). Evaluation of 7SL RNA gene sequences for the identification of Leishmania spp. American Fournal of Tropical Medicine and Hygiene 72, 415-420.

Zemanova, E., Jirku, M., Mauricio, I. L., Horak, A., Miles, M. A. and Lukes, J. (2007). The Leishmania donovani complex: genotypes of five metabolic enzymes (ICD, ME, MPI, G6PDH, and FH), new targets for multilocus sequence typing. International Fournal for Parasitology 37, 149-160. doi:10.1016/j. ijpara.2006.08.008

Zemanova, E., Jirku, M., Mauricio, I. L., Miles, M. A. and Lukes, J. (2004). Genetic polymorphism within the Leishmania donovani complex: correlation with geographic origin. American Yournal of Tropical Medicine and Hygiene 70, 613-617. 